\title{
Article
}

\section{Infigratinib (BGJ 398), a Pan-FGFR Inhibitor, Targets P-Glycoprotein and Increases Chemotherapeutic-Induced Mortality of Multidrug-Resistant Tumor Cells}

\author{
Sergei Boichuk ${ }^{1,2,3, *(\mathbb{D})}$, Pavel Dunaev ${ }^{1}$, Ilshat Mustafin ${ }^{4}$, Shinjit Mani ${ }^{1}$ (D), Kirill Syuzov ${ }^{1}$ (D), Elena Valeeva ${ }^{2}$, \\ Firuza Bikinieva ${ }^{1}$ (D) and Aigul Galembikova ${ }^{1}$ (D)
}

1 Department of Pathology, Kazan State Medical University, 420012 Kazan, Russia; dunaevpavel@mail.ru (P.D.); shinjit.mani@gmail.com (S.M.); grop2019@gmail.com (K.S.); f.bikinieva@kazangmu.ru (F.B.); ailuk000@mail.ru (A.G.)

2 Central Research Laboratory, Kazan State Medical University, 420012 Kazan, Russia; elena.valeeva@kazangmu.ru

3 Department of Radiotherapy and Radiology, Faculty of Surgery, Russian Medical Academy of Continuous Professional Education, 125993 Moscow, Russia

4 Department of Biochemistry, Kazan State Medical University, 420012 Kazan, Russia; ilshat.mustafin@kazangmu.ru

* Correspondence: boichuksergei@mail.ru; Tel.: +7-917-397-80-93; Fax: +7-843-236-06-52

check for updates

Citation: Boichuk, S.; Dunaev, P.; Mustafin, I.; Mani, S.; Syuzov, K.; Valeeva, E.; Bikinieva, F.;

\section{Galembikova, A. Infigratinib (BGJ} 398), a Pan-FGFR Inhibitor, Targets P-Glycoprotein and Increases Chemotherapeutic-Induced Mortality of Multidrug-Resistant Tumor Cells. Biomedicines 2022, 10, 601 . https: / /doi.org/10.3390/ biomedicines10030601

Academic Editor: Radka Vaclavikova

Received: 10 February 2022 Accepted: 28 February 2022 Published: 3 March 2022

Publisher's Note: MDPI stays neutral with regard to jurisdictional claims in published maps and institutional affiliations.

Copyright: (C) 2022 by the authors. Licensee MDPI, Basel, Switzerland. This article is an open access article distributed under the terms and conditions of the Creative Commons Attribution (CC BY) license (https:// creativecommons.org/licenses/by/ $4.0 /)$.
Abstract: The microtubule-targeting agents (MTAs) are well-known chemotherapeutic agents commonly used for therapy of a broad spectrum of human malignancies, exhibiting epithelial origin, including breast, lung, and prostate cancer. Despite the impressive response rates shortly after initiation of MTA-based therapy, the vast majority of human malignancies develop resistance to MTAs due to the different mechanisms. Here, we report that infigratinib (BGJ 398), a potent FGFR1-4 inhibitor, restores sensitivity of a broad spectrum of ABCB1-overexpressing cancer cells to certain chemotherapeutic agents, including paclitaxel (PTX) and doxorubicin (Dox). This was evidenced for the triple-negative breast cancer (TNBC), and gastrointestinal stromal tumor (GIST) cell lines, as well. Indeed, when MDR-overexpressing cancer cells were treated with a combination of BGJ 398 and PTX (or Dox), we observed a significant increase of apoptosis which was evidenced by an increased expression of cleaved forms of PARP, caspase-3, and increased numbers of Annexin V-positive cells, as well. Moreover, BGJ 398 used in combination with PTX significantly decreased the viability and proliferation of the resistant cancer cells. As expected, no apoptosis was found in ABCB1overexpressing cancer cells treated with PTX, Dox, or BGJ 398 alone. Inhibition of FGFR-signaling by BGJ 398 was evidenced by the decreased expression of phosphorylated (i.e., activated) forms of FGFR and FRS-2, a well-known adaptor protein of FGFR signaling, and downstream signaling molecules (e.g., STAT-1, -3, and S6). In contrast, expression of MDR-related ABC-transporters did not change after BGJ 398 treatment, thereby suggesting an impaired function of MDR-related ABC-transporters. By using the fluorescent-labeled chemotherapeutic agent PTX-Alexa488 (Flutax-2) and doxorubicin, exhibiting an intrinsic fluorescence, we found that BGJ 398 substantially impairs their efflux from MDR-overexpressing TNBC cells. Moreover, the efflux of Calcein AM, a well-known substrate for ABCB1, was also significantly impaired in BGJ 398-treated cancer cells, thereby suggesting the ABCB1 as a novel molecular target for BGJ 398. Of note, PD 173074, a potent FGFR1 and VEGFR2 inhibitor failed to retain chemotherapeutic agents inside ABCB1-overexpressing cells. This was consistent with the inability of PD 173074 to sensitize Tx-R cancer cells to PTX and Dox. Collectively, we show here for the first time that BGJ 398 reverses the sensitivity of MDR-overexpressing cancer cells to certain chemotherapeutic agents due to inhibition of their efflux from cancer cells via ABCB1-mediated mechanism.

Keywords: ABC-transporters; paclitaxel; doxorubicin; FGFR-inhibitors; resistance; apoptosis; sensitization 


\section{Introduction}

Acquired resistance to the chemotherapeutic and targeted drugs remains the biggest challenge in clinical oncology. Despite the specific mechanisms involved in tumor resistance to the conventional and targeted-based therapies (e.g., secondary mutations of the targeted proteins), the malignancies might also acquire the universal mechanisms rendering them unsusceptible to the broad spectrum of anti-cancer agents. These mechanisms result in multidrug-resistance (MDR), which involves comprehensive and overlapping mechanisms, including (1) deregulation of apoptosis [1-3]; (2) epithelial-mesenchymal transition (EMT) [4-6]; (3) enhanced DNA damage repair (DDR) [7]; (4) overexpression of drug efflux pumps in cancer cells. This is characterized by an increased expression of ATPbinding cassette $(\mathrm{ABC})$ transporters. Despite 48 members of the $\mathrm{ABC}$ transporter family being currently described, the clinical evidence of drug resistance was shown mainly for 3 members. This includes overexpression of the ABCB1, which is also known as multidrug resistance (MDR)-associated transporter P-glycoprotein (or MDR-1), ABCC1 (also known as multidrug resistance-associated protein 1 (MRP1)), and ABCG2 (also known as a breast cancer resistance protein (BCRP). These proteins are responsible for removing the drugs out of the cell to decrease their intracellular concentration, thus reducing the effectiveness of the chemotherapeutic agents. In particular, several groups of anti-cancer drugs are known as the substrates of ABCB1 and include vinca alkaloids, anthracyclines, epipodophyllotoxins, and taxanes [8]. Moreover, overexpression of ABCB1 in cancer cells can confer resistance to tyrosine kinase inhibitors (TKIs) such as imatinib and dasatinib $[9,10]$. Thus, overexpression of P-glycoprotein in cancer cells was shown as one of the well-known factors associated with poor therapeutic response in patients receiving cytotoxic and targeted-based anticancer therapies. ABCG2 also plays an important role in the development of MDR in cancer cells by providing the effective efflux of a broad spectrum of chemotherapeutic agents, including anthracyclines, methotrexate, mitoxantrone, topotecan, irinotecan, flavopiridol, and camptothecin-derived topoisomerase I inhibitors [11,12]. ABCC1, another member of the $C$ subfamily of ABC transporters, has been shown to transport vinca alkaloids, various neutral and anionic hydrophobic compounds, and products of Phase II drug metabolism, including many glutathione and glucuronide conjugates [13-16]. Thus, targeting of ABC transporters was also suggested as a prospective therapeutic approach to overcome tumor resistance to the chemotherapeutic agents and targeted drugs [17-20]. However, most of the attempts to inhibit the function of $\mathrm{ABC}$ transporters lead to disappointing results for both the first (e.g., verapamil, cyclosporine A) and second (e.g., valspodar, biricodar, dexverapamil) generations of the $\mathrm{ABC}$ inhibitors, because of their unacceptable levels of toxicity and/or lower potential inhibiting effects. Despite second-generation inhibitors exhibited highest affinity and specificity for ABCB1 transporter, these inhibitors were also shown to be the substrates for other ABC transporters, such MRP-1, and BCRP, and drugmetabolizing enzymes such as CYP 3A4, thereby hampering their development due to the significant pharmacokinetic alterations and undesirable drug-drug interactions [21,22]. Thus, third-generation inhibitors were developed (e.g., tariquidar (XR9576), zosuquidar (LY335979), and elacridar (GF120918) and displayed the highest affinity to ABCB1 and fewer pharmacokinetic interactions [23]. Over the years several of the above-mentioned $\mathrm{ABC}$ inhibitors reached clinical evaluation, however, in the vast majority of cases, the results obtained were disappointing. For example, phase III trials with tariquidar were abandoned due to the toxicity [24]. The results of a phase III clinical trial with zosuquidar did not illustrate the benefits for the patients with acute myeloid leukemia [25]. Several clinical trials were prematurely terminated due to unexpected side effects, toxicity from adverse interaction with anticancer drugs, poor solubility, and limitations in the design of the studies (e.g., the patients were not selected based on tumor expression of ABC transporters, the absence of clinically validated imaging assays to detect $A B C$ transporter function, etc.) [26,27]. As a result, no inhibitor of ABC transporters has been approved for clinical use so far. Therefore, it's an urgent need for clinical oncology to find out the potent and effective inhibitors with minimal adverse effects. 
Despite TKIs acting on the catalytic site of the tyrosine kinase domain by competing with ATP binding, which blocks the kinase activity, interferes with downstream signaling pathways, and subsequently impairs cell proliferation and survival, the multiple reports also illustrate that TKIs can also interfere with the function of ABC transporters. For example, nilotinib (Tasigna), a Bcr-Abl inhibitor approved for therapy of chronic myelogenous leukemia (CML) has been shown to inhibit the function of ABCB1-, ABCG2-, and ABCC10 transporters and reverses drug resistance [28,29]. Rivoceranib, a potent inhibitor of vascular endothelial growth factor receptor 2 (VEGFR-2), has been shown to reverse ABCB1- and ABCG2-mediated resistance in cancer cells [30,31]. Lapatinib (Tykerb), a dual tyrosine kinase inhibitor that interrupts the HER2/neu and epidermal growth factor receptor (EGFR) pathways, was approved for the use of breast cancer and other solid tumors, and was also shown to inhibit ABCB1- and ABCG2-mediated MDR in cancer cells [32].

Similarly, inhibition of FGF-signaling by TKIs was also shown to be an effective therapeutic approach for cancer patients. Indeed, the promising results of pemigatinib and infigratinib were shown in advanced unresectable cholangiocarcinoma harboring FGFR2 fusions or rearrangements [33-35], and erdafitinib in metastatic urothelial carcinoma with FGFR2 and FGFR3 genetic aberrations [36]. Recent studies have shown the presence of overactivation of the FGFR-mediated pathway in the multiple TNBC cell lines and TNBC patient samples; this contributes to the disease progression, metastasis, and chemoresistance [37-39]. Also, recent findings pointed out the presence of an activated FGFR-mediated pathway in the HCC 1806 cell line resistant to a PARP inhibitor [40]. Thus, the anti-tumor activities of FGFR inhibitors might be considered as the prospective therapeutic option for TNBC therapies, especially in chemoresistant settings. This therapeutic option might be effectively realized due to the activity of FGFR inhibitors as potent inhibitors of ABC-transporters. However, limited data illustrating this possibility is currently available. For example, it was shown that PD 173074, FGFR1 inhibitor, reversed ABCB1-mediated multidrug resistance to colchicine $(\mathrm{CH})$, paclitaxel (PTX), and vinblastine (Vin) in $\mathrm{CH}$-resistant human epidermoid carcinoma cell subline and ABCB1-overexpressing HEK293 cells [41].

In this study, we examined whether infigratinib (BGJ 398), a potent and selective FGFR1-4 inhibitor can reverse the resistance of ABCB1-overexpressing cancer cells to the conventional chemotherapeutic agents PTX and doxorubicin (Dox), a topoisomerase II inhibitor. For this purpose, we used ABCB1-overexpressing PTX-resistant basal-like TNBC cell line HCC 1806-Tx-R, which was previously established in our laboratory [42]. Given that a broad spectrum of tumorous tissues acquires MDR phenotype due to the repeated exposure to chemotherapeutic agents, we also expanded our study to the cancer cell lines that originated from the epithelium of the gastrointestinal tract and bone tissues. Thus, we also included in our study ABCB1-overexpressing gastrointestinal stromal tumor (GIST T-1 Tx-R) cell subline, which was also generated in our laboratory, as shown elsewhere [43].

Here, we show for the first time that Infigratinib (BGJ 398), effectively re-sensitizes MDR-overexpressing cancer cells to certain chemotherapeutic agents and induces their apoptosis when used in combination with PTX or Dox. This effect of BGJ 398 was due to its ability to inhibit the efflux of these chemotherapeutic agents from cancer cells via the ABCB1-mediated mechanism.

\section{Materials and Methods}

\subsection{Chemical Compounds}

BGJ 398 and PD 173074 were purchased in SelleckChem (Houston, TX, USA). Paclitaxel (PTX) and doxorubicin (Dox) were obtained from Sigma-Aldrich (Merck KGaA, Darmstadt, Germany). Alexa488-conjugated PTX (Flutax-2) and was purchased in (Thermo Fisher Scientific, Inc., Waltham, MA, USA). Calcein acetoxymethyl ester (AM) was obtained from Abcam (Abcam, Cambridge, MA, USA). The chemicals were dissolved in dimethyl sulfoxide (DMSO) according to the manufacturer's recommendations. 


\subsection{Cell Lines and Culture Conditions}

The human basal-like TNBC cell line HCC 1806 was purchased from the American Type Culture Collection (Manassas, VA, USA). Paclitaxel (PTX)- resistant ABCB1overexpressing TNBC subline (HCC 1806-Tx-R) was established in our laboratory, as shown elsewhere [42]. GIST T-1 was established from a metastatic pleural tumor from a stomach GIST and contained a heterozygous 57-base pair deletion (V570-Y578) in the KIT exon 11 [44]. PTX-resistant ABCB1-overexpressing GIST T-1R subline was also established in our laboratory via stepwise treatment with increasing concentrations of PTX, as shown elsewhere [43]. The cell lines indicated above were maintained in RPMI-1640 medium (Paneco, Moscow, Russia) supplemented with 15\% fetal bovine serum (Gibco; Thermo Fisher Scientific, Inc., Waltham, MA, USA), $50 \mathrm{U} / \mathrm{mL}$ penicillin and $50 \mu \mathrm{g} / \mathrm{mL}$ streptomycin. The cell lines were cultured at $37{ }^{\circ} \mathrm{C}$ in a humidified atmosphere of $5 \% \mathrm{CO}_{2}$ in an incubator (LamSystems, Miass, Russia).

\subsection{Antibodies}

The primary antibodies used for western blotting were anti-PARP (cat. no. 436400; Invitrogen; Thermo Fisher Scientific, Inc., Waltham, MA, USA), cleaved caspase-3 (cat. no. 9661S), phospho-NuMA Ser395 (cat. no. 3429), phospho-Histone H3 Ser10 (cat. no. 53348), phospho-FGFR Tyr 653/654 (cat. no. 3471), phospho- Tyr196 (cat. no. 3864), phospho-AKT S473 (cat. no. 4060P), phospho-p44/42 MAPK (Erk1/2) Thr202/Tyr204 (cat. no. 4370S), phospho-STAT-1 Ty701 (cat. no. 7649), phospho-STAT-3 Tyr705 (cat. no. 9145), phosphoGSK3B Ser9 (cat no. 5558) phospho-S6 Ribosomal Protein Ser235/236 (cat. no. 4858T) (Cell Signaling Technology Inc., Danvers, MA, USA), anti-ABC subfamily G member 2 (cat. no. sc-58222), MDR-1 (cat. no. sc-55510), MRP-1 (cat. no. sc-18835) (Santa Cruz Biotechnology, Dallas, TX, USA), and beta-actin (cat. No. A00730-200, GenScript, Piscataway, NJ, USA); HRP-conjugated secondary antibodies, anti-mouse immunoglobulin (Ig)G (cat. no. sc-2005) and anti-rabbit IgG (cat. no. sc-2004), were purchased from Santa Cruz Biotechnology, Dallas, TX, USA.

\subsection{Western Blotting Analysis}

To examine the protein expression in parental and Tx-R cells, whole-cell lysates (WCL) were prepared by scraping the cells growing as monolayer into radio-immunoprecipitation buffer (RIPA buffer) (25 mM Tris-HCl pH 7.6, 5 mM nEDTA, 150 mM NaCl, 0.1\% SDS, 1\% NP-40, 1\% sodium deoxycholate) supplemented with the cocktail of protease and phosphatase inhibitors. The cellular lysates were further incubated for $1 \mathrm{~h}$ at $4{ }^{\circ} \mathrm{C}$ and clarified by centrifugation for $30 \mathrm{~min}$ at $11,400 \mathrm{rpm}$ at $2{ }^{\circ} \mathrm{C}$. The protein concentrations in WCL were calculated by the Bradford assay. The protein samples $(20 \mu \mathrm{g})$ were loaded on the $4-12 \%$ Bis-Tris or 3-8\% Tris-acetate NuPAGE gels (Invitrogen, Carlsbad, CA, USA) and upon completion of electrophoresis transferred to a nitrocellulose membrane (Bio-Rad, Hercules, CA, USA), membranes were probed with primary (1:1000 and incubated overnight at $\left.4{ }^{\circ} \mathrm{C}\right)$, and secondary antibodies (1:1000 and incubated for $1 \mathrm{~h}$ at room temperature) and visualized by enhanced chemiluminescence (Western Lightning Plus-ECL reagent, Perkin Elmer, Waltham, MA, USA). The densitometry analysis of Western blotting images was performed by NIH Image software, version 1.49 (Bethesda, MD, USA).

\subsection{Crystal Violet Staining}

Cells were seeded into p100 plates and treated with BGJ $398(1 \mu \mathrm{M})$, PD 173074 $(100 \mu \mathrm{M})$ and PTX $(1 \mu \mathrm{M})$ alone or in combination for $96 \mathrm{~h}$. Cell medium was aspirated and $5 \mathrm{~mL}$ of $0.5 \%$ crystal violet staining solution to each well was added, and incubated for $20 \mathrm{~min}$ at room temperature. Plates were washed 4 times in a stream of tap water and kept inverted on filter paper to air-dry $3 \mathrm{~mL}$ of $1 \%$ SDS was added in each plate and kept on a shaker at room temperature for $1 \mathrm{~h}$. The optical density was measured at $570 \mathrm{~nm}$ wavelength using a MultiScan FC plate reader (Thermo Fisher Scientific, Waltham, MA, USA). 


\subsection{RNA Extraction and Reverse Transcription-Quantitative Polymerase Chain Reaction $(R T-q P C R)$}

Parental and Tx-R cancer cells were seeded in p100 plates and treated with TKIs (BGJ 398 or PD 173074) and chemotherapeutic agents (PTX or Dox) alone or in combination for $48 \mathrm{~h}$. TRIzol reagent (cat. no. BC032; Invitrogen; Thermo Fisher Scientific, Inc.) was used to extract total RNA, according to the manufacturer's protocol, and re-suspended in diethyl pyrocarbonate-treated $\mathrm{H}_{2} \mathrm{O}$. RNA was reverse transcribed to cDNA using the Moloney murine leukemia virus reverse transcriptase kit (cat. no. SK021; Evrogen JSC, Moscow, Russia) following manufacturer's protocol, and further subjected to quantitativePCR. $1 \mu \mathrm{L}$ template cDNA in total was used in the qPCR reaction, with 5x qPCRmix-HS SYBR (Evrogen JSC, Moscow, Russia) and forward and reverse primer $10 \mathrm{mM}$ of each. The sequences of the primers and thermal cycling conditions used in this study are shown elsewhere [42]. qPCR was performed using the CFX96 Real-Time detection system (BioRad Laboratories, Inc., Hercules, CA, USA). Assays for each experience sample were processed in parallel with reference gene GAPDH and the relative levels of each mRNA were normalized regarding GAPDH. The $\triangle \triangle \mathrm{Cq}$ method was then used to calculate relative gene expression [45].

\subsection{Cellular Survival Assay}

Parental and Tx-R cancer cells (e.g., HCC 1806 and GIST-T-1) were plated on 96-well flat-bottomed plates (Corning Inc. Corning, NY, USA) and allowed to attach and grow for $24 \mathrm{~h}$ before treatment with BGJ 398, PD 173074, PTX or Dox that were introduced into the cell culture for $72 \mathrm{~h}$ with specified concentrations alone or in combination. Half-inhibitory concentrations $\left(\mathrm{IC}_{50}\right)$ further named as $\mathrm{IC}_{50}$ values were defined as the concentration of the anti-cancer drug required to inhibit cellular growth by $50 \%$. This data was normalized to the DMSO-treated control cells. To calculate the $\mathrm{IC}_{50}$ values of the chemotherapeutic agents indicated above, MTS reagent (Promega, Madison, WI, USA) was introduced into the cell culture for $1 \mathrm{~h}$ to assess the live cell numbers. The viability of the cells was assayed at $492 \mathrm{~nm}$ on a MultiScan FC plate reader (Thermo Fisher Scientific, Waltham, MA, USA). $\mathrm{IC}_{50}$ values were determined by using the $\mathrm{IC}_{50}$ Tool Kit (http://ic50.tk/, accessed on 10 January 2022).

\subsection{Flow Cytometry}

FACs analysis was used to examine the inhibition of P-gp-mediated transport from BGJ 398 or PD 173074-treated parental and Tx-R cancer cells. For this purpose, fluorescent compound Calcein AM was used. Briefly, cells were preincubated with one of FGFR inhibitors (BGJ 398-20 $\mu \mathrm{M}$ or PD 173074-50 $\mu \mathrm{M}$ ) for $60 \mathrm{~min}$. After that, cells were trypsinized, centrifuged, and were incubated with $100 \mathrm{nM}$ Calcein AM (in phosphate-buffered saline) for $30 \mathrm{~min}$ at a temperature of $37^{\circ} \mathrm{C}$. After centrifugation, cells were incubated in culture medium in the presence of the FGFR inhibitors for $60 \mathrm{~min}$ at a temperature of $37^{\circ} \mathrm{C}$. Lastly, cells were washed with ice-cold phosphate-buffered saline and analyzed by flow cytometer BD FACSCanto II (Becton Dickinson Biosciences, Franklin Lakes, NJ, USA) by using BD FACSDiva Software, version 7.0.

To assess the intensity of Dox- or Flutax-2-mediated fluorescence, cells were preincubated with one of FGFR inhibitors (BGJ 398-20 $\mu \mathrm{M}$ or PD 173074-50 $\mu \mathrm{M}$ ) for $60 \mathrm{~min}$ and further exposed to $40 \mu \mathrm{M}$ of Dox or $3 \mu \mathrm{M}$ of Flutax-2 (Alexa-488 labeled paclitaxel). After $60 \mathrm{~min}$, chemotherapeutic agents were extensively washed out with FBS-free culture medium, cells were further cultured for $30 \mathrm{~min}$ in presence of FGFR inhibitors and analyzed. Cells were analyzed by flow cytometer BD FACSCanto II (Becton Dickinson Biosciences, Franklin Lakes, NJ, USA) by using BD FACSDiva Software.,version 7.0

The number of apoptotic cells were counted by using Muse Annexin V Et Dead Cell Kit (Merck KGaA, Darmstadt, Germany) according to the manufacturer's instructions. Unstained and single-stained untreated cells were used as controls. Cells were analyzed in a Muse Cell Analyzer (Merck KGaA, Darmstadt, Germany). 
For all the experiments indicated above at least 10,000 events were acquired for each sample. Results were presented as the percentage of desired cells relative to the total number of cells as mean \pm standard deviation 4 biological repeats.

\subsection{Immunofluorescence Staining}

Cells were seeded on glass coverslips coated with poly-L-lysine (Sigma-Aldrich, St. Louis, MO, USA) and allowed to attach for $48 \mathrm{~h}$ before treatment. The cells were first incubated with one of FGFR inhibitors (BGJ 398 - 20 $\mu \mathrm{M}$ or PD 173074-50 $\mu \mathrm{M}$ ) for $60 \mathrm{~min}$ and then incubated with $40 \mu \mathrm{M}$ of Dox or $3 \mu \mathrm{M}$ of Flutax-2 (Alexa-488 labeled paclitaxel) for an additional $60 \mathrm{~min}$. After the wash-out with a pre-warmed FBS-free culture medium, the cells were additionally incubated in presence of FGFR inhibitors for $30 \mathrm{~min}$. The nonfixed slides were counterstained with $3 \mu \mathrm{g} / \mathrm{mL}$ Hoechst 33342 (Thermo Fisher Scientific, Inc., Waltham, MA, USA) for 5 min to outline the nuclei and processed for fluorescence microscopy to obtain the merged images that were visualized on an Olympus BX63 fluorescence microscope (Olympus, Tokyo, Japan). Images were captured using a Spot advanced imaging system.

\subsection{Molecular Docking}

To identify the potential binding sites of BGJ 398 on the ABCB1, the molecular docking procedure was performed by using Schrodinger molecular modeling software, version 2021-2 (Schrödinger, Inc., New York, NY, USA, 2021). The Glide Docking XP mode was used to find the ABCB1-BGJ 398 supramolecular complex with minimal energy scoring function. The ABC1 structure (no. 6QEX) was downloaded from the Protein Data Bank (6QEX. Available online: https:/ / www.rcsb.org/structure/6QEX, accessed on 28 February 2022). The protein structure was prepared before docking using the Protein Preparation Wizard module. Initial ligand structures were optimized using standard preparation procedures in the LigPrep module. Standard Induced FIT Docking Protocol is used to generate possible induced ABCB1 conformations [46]. The representative conformation of the ligand-receptor complex was selected based on the maximum IDF score. The molecular mechanics/generalized Born surface area (MM-GBSA) method was used as a post-docking validation tool [47]. Based on the XP docked complex, we calculated the binding free energy ( $\Delta$ Gbind) and ligand strain energy of each drug.

\subsection{Statistics}

All the experiments were repeated a minimum of 3 times. The results are presented as the mean \pm standard error (SE) for each group. Statistical analyses (Student's $t$-test) were performed using Statistical software program version 7.0 (S.A. Glantz, McGraw Hill Education, NY, USA). $p<0.05$ was considered to indicate a statistically significant difference. The degree of combination effects was quantified by using the R-package of the computational tool SynergyFinder (https:/ / bioconductor.org/packages/release/bioc/ html/synergyfinder.html). Highest single agent model (HSA) was used to calculate the synergy [48]. Means of normalized protein levels were compared by using the analysis of variance (ANOVA) with subsequent pairwise comparisons (Tukey HSD test) in R software, version 4.1.2.(R Foundation for Statistical Computing, Vienna, Austria; URL https: / www. R-project.org/).

\section{Results}

\subsection{Tx-R Cancer Cells Exhibit the Increased Expression of ABC-Transporters}

Given that the tumor's resistance to certain chemotherapeutic agents might be due to the overexpression of ABC-transporters regulating the efflux of chemotherapeutic drugs from cancer cells, we initially examined whether the expression of 3 major ABC-transporters (e.g., ABCB1, ABCG2 and ABCC1) was increased in PTX-resistant (Tx-R) cancer cells. For this purpose, we used Tx-R cancer sublines previously generated in our laboratory. The $\mathrm{IC}_{50}$ values for PTX, Dox and BGJ 398 in parental and Tx-R triple-negative breast cancer 
(TNBC) cell lines and gastrointestinal stromal tumor (GIST) cells are shown in Table 1. For example, we observed a substantial ( 80-fold) increase of $\mathrm{IC}_{50}$ value for Dox in Tx-R HCC 1806 cells, when compared with naive HCC 1806. Similarly, 25-fold increase of $\mathrm{IC}_{50}$ value for PTX was found in Tx-R HCC 1806 cells. This was in concordance with a significant increase of ABCB1 (i.e., P-glycoprotein) expression in all Tx-R cancer sublines when compared to parental cancer cells (Figure 1). Similar to ABCB1, the expression of ABCG2 was also increased in the HCC 1806 subline when compared with its parental counterpart (Figure 1A). This data was in concordance with an increased expression of ABCB1 mRNA in both HCC 1806 and GIST Tx-R cell sublines (Supplementary Table S1). Moreover, the MRP-1, 2 and -5 mRNAs levels were also significantly increased in HCC 1806-Tx-R (Supplementary Table S1). In contrast to the breast cancer cell lines, a moderate increase of $A B C B 1$ and $M R P-1$ and -5 was observed in Tx-R GIST cells when compared with their parental GIST T-1 cells ( Supplementary Table S1). As expected, minor antiproliferative and cytotoxic activities of BGJ 398 was observed for both parental and Tx-R sublines, thereby revealing an absence of activating mutations in the FGFRs in both HCC 1806 and GIST T-1 cells.

Table 1. $\mathrm{IC}_{50}$ values for PTX and Dox in parental and Tx-R triple-negative breast cancer (TNBC) and gastrointestinal stromal tumor (GIST) cell lines.

\begin{tabular}{|c|c|c|c|c|}
\hline Chemical Compounds & Cell Line & Parental & Tx-R & Fold Increase \\
\hline \multirow{2}{*}{$\operatorname{PTX}(\mu \mathrm{M})$} & HCC 1806 & $0.22 \pm 0.01$ & $5.4 \pm 1$ & 24.5 \\
\hline & GIST T-1 & $<0.01$ & $0.46 \pm 0.08$ & $>46$ \\
\hline \multirow{2}{*}{$\operatorname{Dox}(\mu \mathrm{M})$} & HCC 1806 & $0.22 \pm 0.004$ & $1.8 \pm 0.5$ & 81.8 \\
\hline & GIST T-1 & $0.04 \pm 0.005$ & $6.5 \pm 1$ & 162.5 \\
\hline \multirow{2}{*}{ BGJ $398(\mu \mathrm{M})$} & HCC 1806 & $12 \pm 1.3$ & $17.6 \pm 3$ & 1.47 \\
\hline & GIST T-1 & $8.8 \pm 1$ & $7.2 \pm 0.2$ & 0.82 \\
\hline
\end{tabular}

A.
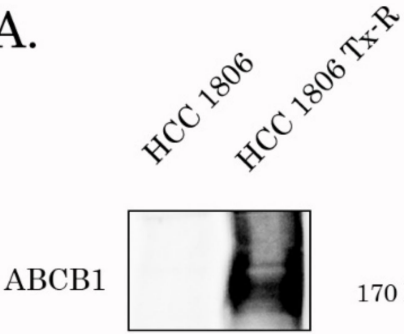

$170 \mathrm{kDa}$

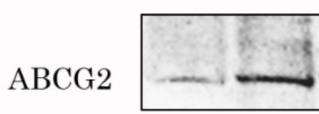

$67-80 \mathrm{kDa}$

MRP1

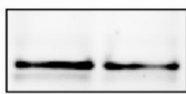

$190 \mathrm{kDa}$

Actin

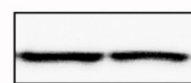

$42 \mathrm{kDa}$
B.
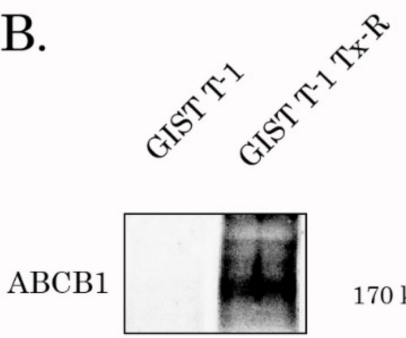

$170 \mathrm{kDa}$

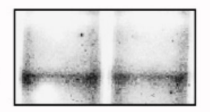

$67-80 \mathrm{kDa}$

MRP1

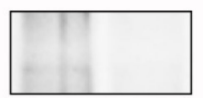

$190 \mathrm{kDa}$

Actin

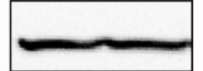

$42 \mathrm{kDa}$

Figure 1. Expression of ABCB1, ABCC1 (MRP-1), and ABCG2 transporters in Tx-R cancer cells vs. Tx-sensitive parental HCC 1806 (A) and GIST T-1 (B) cells. Actin stain was used as a loading control.

Thus, the resistance to PTX and Dox in TNBCs and GIST sublines indicated above might be due to the increased expression of ABC-transporters, in particular, ABCB1 protein. 


\subsection{PTX-Resistant Cancer Cells Exhibit an Increased Efflux of Chemotherapeutic Drugs}

To corroborate these findings, we examined whether an increased expression of ABCtransporters in Tx-R cancer cell lines mediate an effective efflux of the chemotherapeutic agents and therefore decrease their sensitivity to PTX and Dox, as was shown in Table 1. For this purpose, naïve vs. resistant TNBCs and GIST were exposed to Alexa 488-labeled PTX (Flutax-2) for $1 \mathrm{~h}$ and after PTX wash-out, the cells were cultured for an additional $1 \mathrm{~h}$ and subjected for immunofluorescence microscopy to examine the intracellular staining of Alexa-488 fluorescence dye. Data shown in Figure 2A, illustrates the increased intensity of Alexa-488 staining in the cytoplasm of cells after PTX treatment. This was observed for naïve (upper panel), but not in resistant HCC 1806 cells (lower panel), thereby revealing an excessive removal of Alexa-488-labeled PTX from Tx-R TNBCs. The similar differences were observed between the naïve vs. resistant TNBCs treated with Dox (Figure 2B). Moreover, an excessive removal of Dox was also observed in Tx-R GIST T-1 cells (Supplementary Figure S1), thereby illustrating the accumulation of certain chemotherapeutic agents in Tx-R cancer cells exhibiting various tissue origin.

A.

HCC 1806

HCC $1806 \mathrm{Tx}-\mathrm{R}$

B.

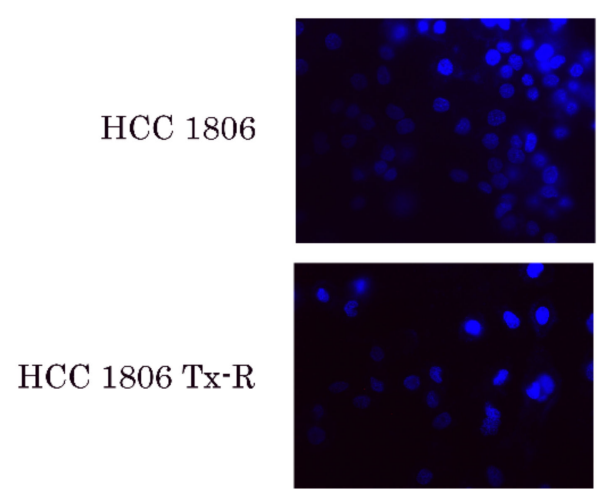

Control
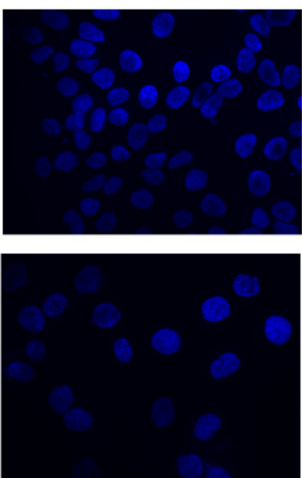

Control

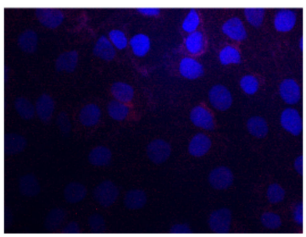

PTX-FL
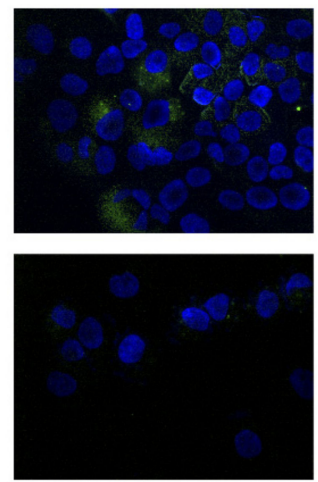

Dox
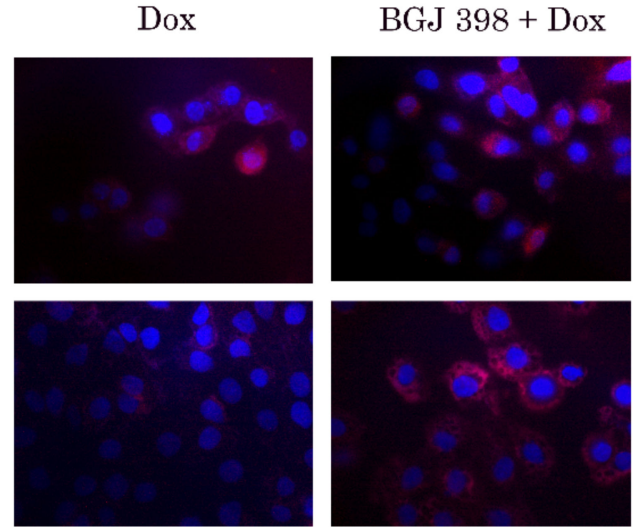

Figure 2. Fluorescence microscopy analysis of the intracellular accumulation of Flutax-2 (PTX-FL) (A) and doxorubicin (DOX) (B) in HCC 1806 parental (upper panels) and Tx-R (lower panels) cells. The cells were first incubated with BGJ $398(20 \mu \mathrm{M})$ (right) or DMSO as a control (middle) for 60min and then incubated with $3 \mu \mathrm{M}$ PTX-FL (A) or $40 \mu \mathrm{M}$ DOX (B) for an additional $60 \mathrm{~min}$. After the wash-out with a pre-warmed FBS-free culture medium, the BGJ 398-treated cells were additionally incubated with BGJ 398 for $60 \mathrm{~min}$. The non-fixed slides were counterstained with Hoechst 33342 (final concentration $3 \mu \mathrm{g} / \mathrm{mL}$ ) for $5 \mathrm{~min}$ to outline the nuclei and processed for fluorescence microscopy to obtain the merged images.

In agreement with immunofluorescence microscopy staining, FACs data illustrated an increase of fluorescence intensity (in FL2 channel) in Dox-treated cells (histograms shown in gray color), when compared to the basal fluorescence levels of the non-treated 
cells (histograms shown in green color) (Figure 3A). Strikingly, the dramatic decrease of the fluorescence intensity of Dox-mediated fluorescence (gray histograms) was found in HCC 1806 Tx-R cells (Figure 3A-right), when compared with the naive HCC 1806 cells (Figure $3 \mathrm{~A}-\mathrm{left}$ ), thereby revealing the decreased intracellular concentration of Dox in Tx-R HCC 1806 cells.

A.
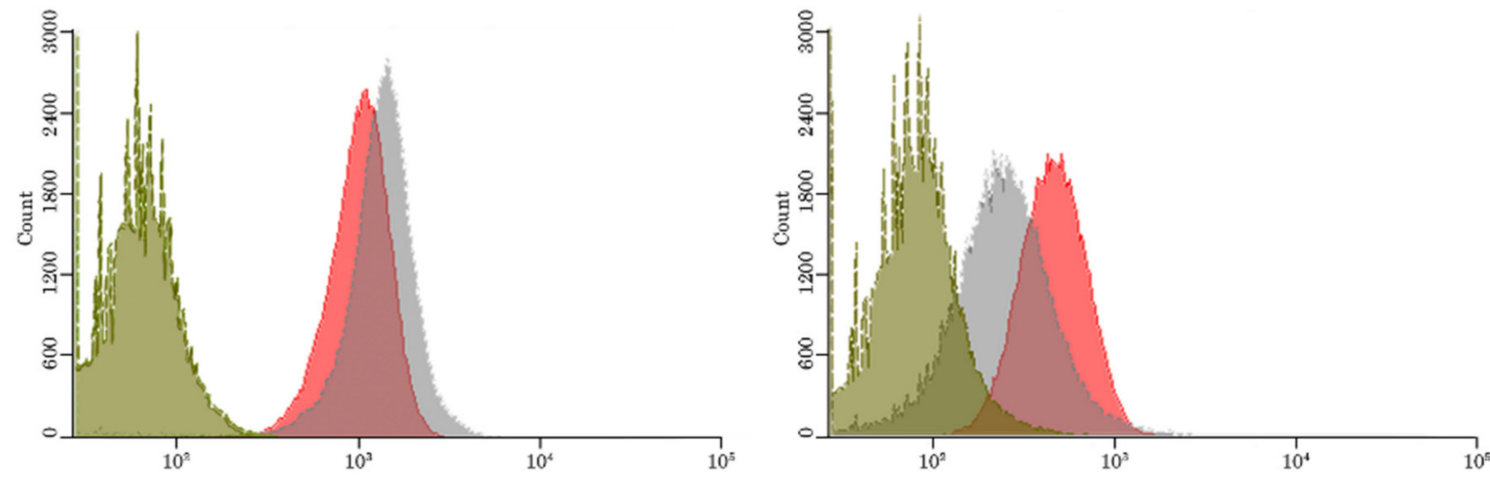

B.
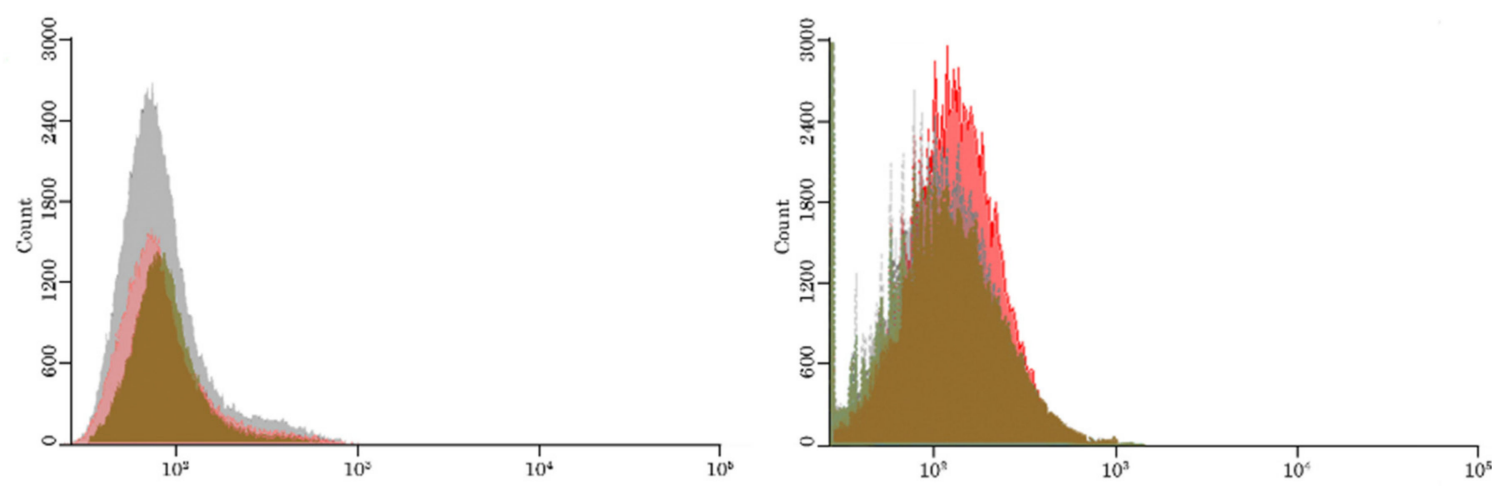

Figure 3. BGJ 398 increases the intracellular accumulation of Dox (A) and Flutax-2 (B) in Tx-R HCC 1806 breast cancer cells. (A) The intracellular accumulation of Dox in drug-sensitive parental HCC 1806 cells (left) and Tx-R HCC 1806 cells (right). The cells were treated with DMSO (green), Dox $(40 \mu \mathrm{M})$ alone (gray) or in combination with BGJ $398(20 \mu \mathrm{M})$ (red). (B) The intracellular accumulation of Alexa-488 labeled PTX (Flutax-2) in drug-sensitive parental HCC 1806 cells (left) and Tx-R HCC 1806 cells (right). The cells were treated with DMSO (green), Flutax-2 ( $3 \mu \mathrm{M})$ alone (gray) or in combination with BGJ $398(20 \mu \mathrm{M})$ (red). The fluorescence intensity was analyzed by FACs. Representative histograms of at least 3 independent experiments are shown.

Similarly, parental HCC 1806 cells exhibited an increased intensity of Alexa-488 staining when compared to the basal levels of the non-treated controls (Figure 3B-left), thereby revealing accumulation of Alexa-488-conjugated PTX in cancer cells. In contrast, minor differences in fluorescence intensity of Alexa-488-labeled PTX were observed between non-treated and PTX-treated HCC 1806 Tx-R cells (Figure 3B-right), thereby suggesting the removal of Alexa-488-labeled PTX from Tx-R HCC 1806 cells.

Taken together, this data illustrates the effective efflux of the chemotherapeutic agents (e.g., PTX and Dox) from Tx-R HCC 1806 breast cancer cell line overexpressing ABCtransporters. 


\subsection{BGJ 398 Enhances the Intracellular Drug Accumulation in Cancer Cells Overexpressing ABC-Transporters}

To examine whether FGFR inhibitors inhibit the efflux of chemotherapeutic agents from Tx-R cancer cells, we performed FACs analysis of cancer cells treated with PTX or Dox alone and in presence of BGJ 398 (the potent and selective inhibitor of FGFR1-4). As was mentioned above, a significant decrease of the intensity Dox-mediated fluorescence was observed in Tx-R HCC 1806 when compared to the parental HCC 1806 cells, thereby revealing an increased efflux of Dox from the resistant TNBC cells (Figure 2B). Strikingly, BGJ 398 increased the intensity of Dox-mediated fluorescence in Tx-R cells (Figure 2B-right lower image), but not in naïve HCC 1806 cells (Figure 2B-right upper image), thereby illustrating an ability of this FGFR inhibitor to attenuate the function of ABC-transporters upregulated in the resistant TNBCs. Similar data were obtained by using the Flutax-2 (Alexa488-labeled PTX). Again, BGJ 398 increased the fluorescence intensity of Alexa488labeled PTX in the resistant (Figure 2A-right lower image), but not in naïve HCC 1806 cells (Figure 3A-right upper image). Strikingly, an ability of BGJ 398 to inhibit the efflux of chemotherapeutic agents from cancer cells was not limited to Tx-R breast cancer cells and was also observed in the $\mathrm{ABC}$-overexpressing $\mathrm{Tx}$ - $\mathrm{R}$ cancer subline exhibiting different tissue origin-e.g., Tx-R GIST T-1 cells (Supplementary Figure S1), thereby suggesting the inhibition of ABC-transporters activity as a common mode of action of BGJ 398. Of note, PD 173074, a well-known FGFR1 and VEGFR2 inhibitor failed to increase intracellular concentrations of Dox in both (parental and Tx-R) HCC 1806 cancer cells, as shown in Supplementary Figure S2. Similar data was obtained for these cancer cell lines treated with Alexa-488-labeled PTX in presence of PD 173074 (data is not shown). This was in consistency with immunofluorescence microscopy staining, illustrating inability of PD 173074 to increase Dox-induced fluorescence in Tx-R cells (e.g., HCC 1806 and GIST T-1) (Supplementary Figure S3A,B, respectively).

Collectively, our data illustrate that BGJ 398, a selective FGFR inhibitor, effectively modulates an efflux of PTX and Dox from Tx-R cancer cells overexpressing ABC-transporters, in particular, $\mathrm{ABCB} 1$.

\subsection{BGJ 398 Attenuates the Activity of the ABCB1 Transporter in Cancer Cells}

Next, we examined directly whether BGJ 398 down-regulates the activity P-glycoprotein in Tx-R resistant cancer cells. For this purpose, we used the Calcein AM, a well-known fluorescent $\mathrm{ABCB} 1$ substrate, and examined its expression in resistant breast cancer cells after BGJ 398 treatment. We found that BGJ 398 effectively inhibited the efflux of Calcein from the resistant TNBCs (Figure 4B), thereby illustrating ABCB1 as a possible molecular target for this FGFR inhibitor. As expected, BGJ 398 have no impact on intracellular concentration of Calcein in naive HCC 1806 cells (Figure 4A). This was in agreement with the absence of ABCB1 expression in parental HCC 1806 cells, as was shown in Figure 1A. In contrast, PD 173074, a well-known FGFR1 and VEGFR2 inhibitor do not have an impact on the efflux of Calcein AM from the naive and resistant TNBC cells, as well (Figure 4A,B, respectively), thereby illustrating the novel ("off-target") effect of BGJ 398 on ABCB1 transporter in TNBC cells.

\subsection{BGJ 398 Restored PTX's Ability to Deregulate Cell Cycle Progression in Tx-R Cancer Cells}

Based on the data illustrating the intracellular accumulation of chemotherapeutic agents and fluorescent dyes in BGJ 398-treated Tx-R TNBCs, we examined whether the extended exposure of cancer cells to PTX will be responsible to deregulate cell cycle progression and restore PTX effect. For this purpose, we analyzed the expression of the proteins that are specifically accumulated in the M-phase. As expected, the expression of histone 3 phosphorylated at residue Ser 10 (pH3 Ser10) was significantly up-regulated after PTX treatment in naïve (Figure 5A), but not in Tx-R cells (Figure 5B), thereby revealing their resistance to PTX. Strikingly, BGJ 398 significantly increased expression of pH3Ser10 in Tx-R cells treated with PTX (Figure 5B), and this effect was not observed in naïve TNBCs. 
Similarly, Tx-R TNBCs treated with PTX in presence of BGJ 398 exhibited an increased expression of pNuma Ser395, a well-known marker of interphase. This data highlights the BGJ 398's potency to restore PTX ability to deregulate the cell cycle progression of Tx-R cancer cells and induce their accumulation in the M-phase.

A.

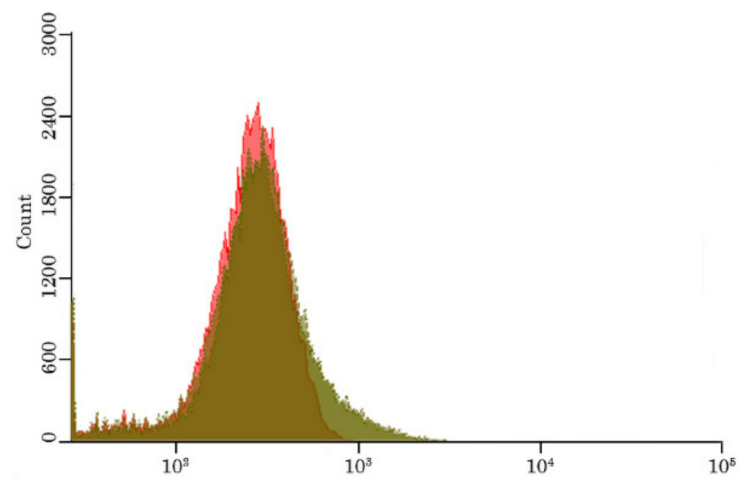

B.

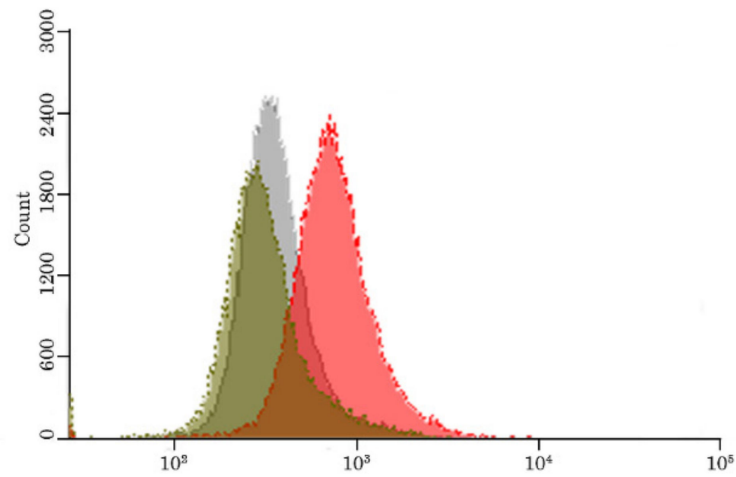

Figure 4. BGJ 398 increases intracellular accumulation of Calcein, an ABCB1 fluorescent substrate, in ABCB1-overexpressing Tx-R HCC 1806 cells. The intracellular accumulation of Calcein, a fluorescent product of the ABCB1 substrate Calcein AM, was determined in the Tx-R HCC 1806 cells (B) and the corresponding drug-sensitive parental HCC 1806 cells (A). The cells indicated above were treated with $100 \mathrm{nM}$ of Calcein AM alone (green) or in combination with $20 \mu \mathrm{M}$ of BGJ 398 (red) or $50 \mu \mathrm{M}$ PD 173074 (gray). The fluorescence intensity was analyzed by FACs. Representative hist grams of at least 3 independent experiments are shown.

A.

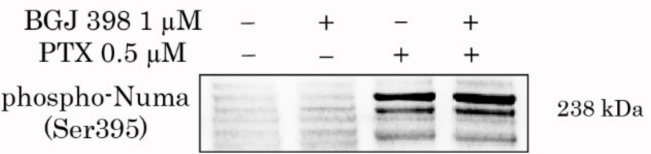

phospho-Histone H3

(Ser10)

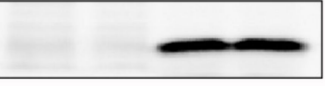

$17 \mathrm{kDa}$

$42 \mathrm{kDa}$

C.

Actin

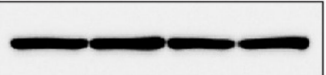

(2)

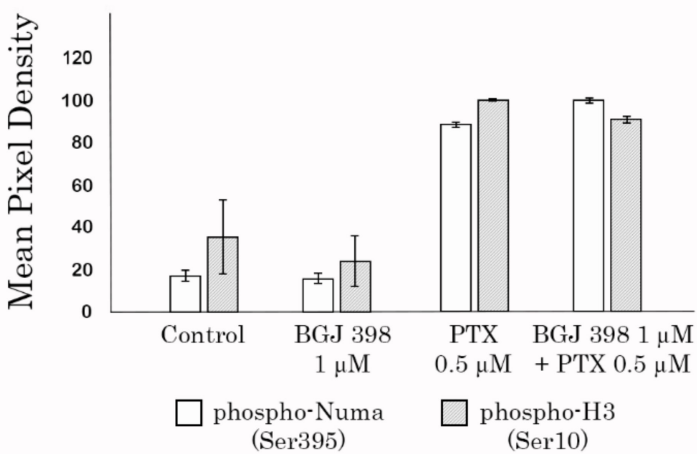

B.

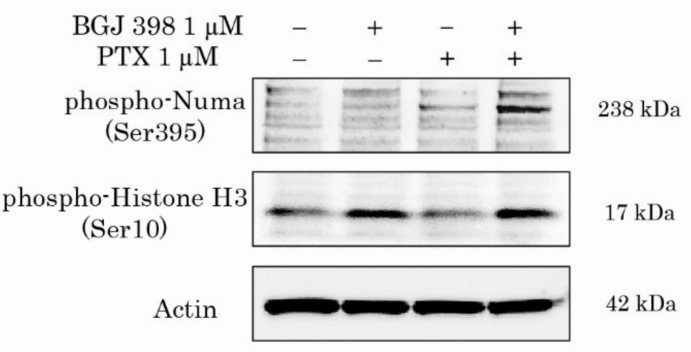

D.

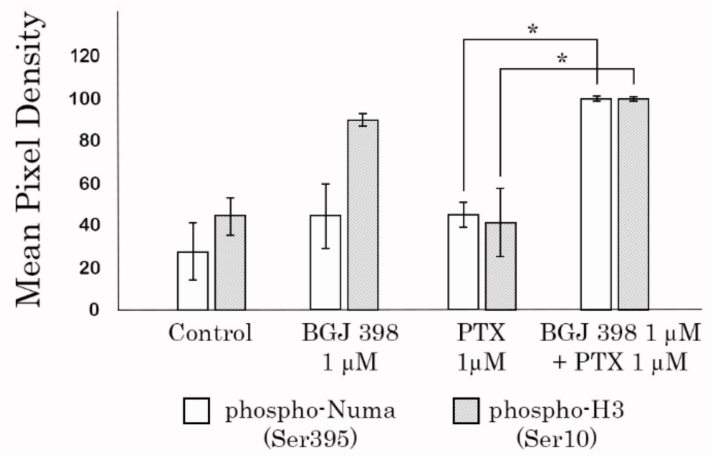

Figure 5. BGJ 398 potentiates accumulation of Tx-R HCC 1806 cancer cells in M-phase after the treatment with PTX. Immunoblot analysis for phospho-NuMA (Ser395) and phospho-H3 (Ser10) in the parental (A) and Tx-R (B) HCC 1806 breast cancer cells after treatment with DMSO (negative control), BGJ 398, PTX alone or in combination for $48 \mathrm{~h}$. Actin stain is used as a loading control. (C,D) Quantification by mean pixel density of pNuMA (Ser395) and $\mathrm{pH} 3$ (Ser10) in the parental (C) and Tx-R (D) HCC 1806 breast cancer cells. Values are means $\pm \mathrm{SD}, n=3 .{ }^{*} p<0.05$ vs. untreated cells. 
This was in agreement with the changes in the morphology of Tx-R HCC 1806 and GIST T-1 cells, which was evidenced by the accumulation of round-shape cells treated with a combination of PTX and BGJ 398 (Supplementary Figure S4A,B, respectively). Indeed, PTX used alone has not a significant impact on the confluence of the cell cultures and the numbers of round-shape cells in both Tx-cancer cell lines, whereas a significant increase in number of these cells was observed when this agent was used in combination with BGJ 398.

\subsection{BGJ 398 Re-Sensitizes ABCB1-Overexpressing Cancer Cells to PTX and Dox}

To examine this possibility, both naïve and Tx-R TNBCs were treated with BGJ398 and PTX alone, or in combination for $96 \mathrm{~h}$ and subjected for western blotting analysis to examine the expression of the well-known markers of apoptosis-the cleaved forms of PARP and caspase-3. As expected, no evidence of apoptosis was observed in both naïve and Tx-R HCC 1806 cells treated with FGFR inhibitor (Figure 6A,B, respectively), whereas PTX treatment resulted in a substantial increase of the cleaved PARP and caspase- 3 in the naive, but not Tx-R HCC 1806 cells (Figure 6A,B, respectively), thereby revealing the resistance to PTX in Tx-R HCC 1806 subline. Strikingly, increased expression of the cleaved forms PARP and caspase-3 was found in Tx-R HCC1 806 cells treated with the combination of PTX and BGJ398 (Figure 6B,D), thereby illustrating BGJ398's potency to reverse sensitivity to PTX in Tx-R TNBCs. Similar effect was found for HCC 1806 cells treated with Dox in presence of BGJ 398 (data is not shown). In consistency with these findings, Tx-R GIST T-1 cells also exhibited increased expression of apoptotic markers (e.g., cleaved forms of PARP and caspase-3) when treated with Dox (or PTX) in presence of BGJ 398 (Supplementary Figure S5).

A.

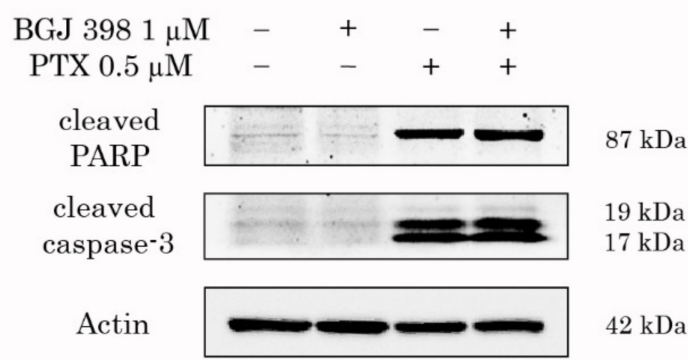

C.

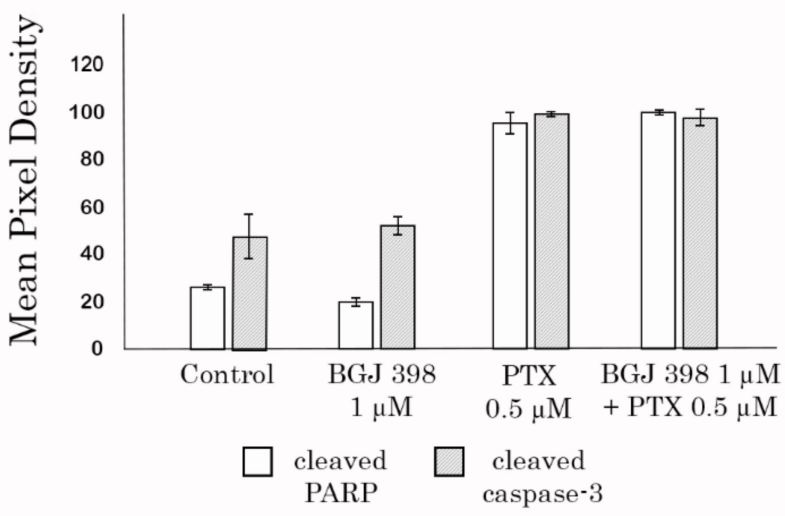

B.

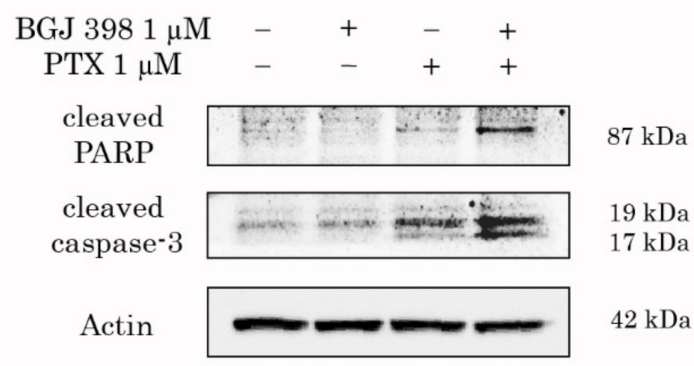

D.

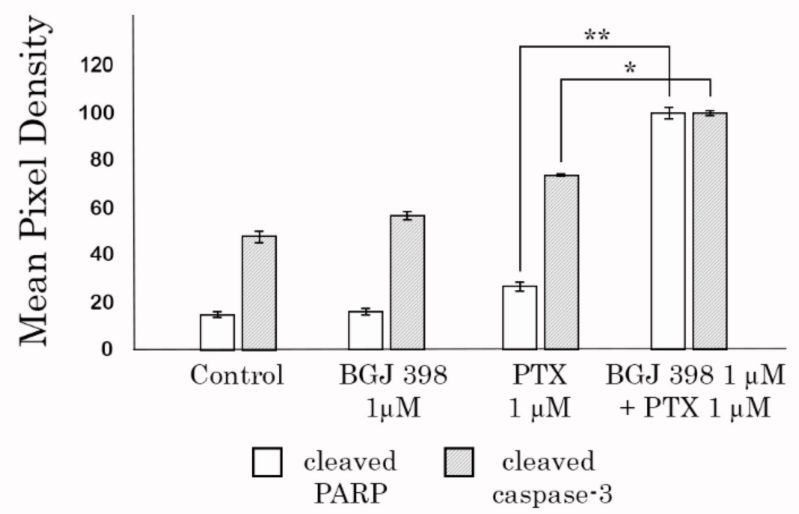

Figure 6. BGJ 398 potentiates apoptosis of Tx-R HCC 1806 cells treated with combination of PTX. Immunoblot analysis for apoptosis markers (cleaved forms of PARP and caspase-3) in naive (A) and Tx-R (B) HCC1 806 breast cancer cells after treatment with DMSO (negative control), PTX, BGJ 398 alone or in combination for $48 \mathrm{~h}$. Actin stain is used as a loading control. (C,D) Quantification by mean pixel density in the cleaved forms of PARP and caspase-3 in naive (C) and Tx-R (D) HCC 1806 breast cancer cells. Values are means $\pm \mathrm{SD}, n=3 .{ }^{*} p<0.05,{ }^{* *} p<0.01$. 
These findings were in consistency with FACs data, illustrating the significant increase of early apoptotic (i.e., Annexin V/PI-negative) cells at $48 \mathrm{~h}$ of post-treatment with the combination of PTX and BGJ 398 (Figure 7A,B). Similar data was obtained in cancer cells treated with Dox in presence of BGJ 398. In contrast, PD 173074 used in combination with PTX or Dox failed to increase apoptosis in Tx-R HCC 1806 cells (Supplementary Figure S6). This was in agreement with our previous data illustrating low potency of this FGFR inhibitor to retain chemotherapeutic agents inside cancer cells (Supplementary Figure S3).

A.

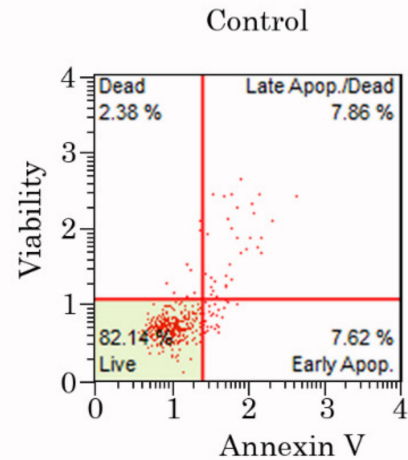

BGJ 398

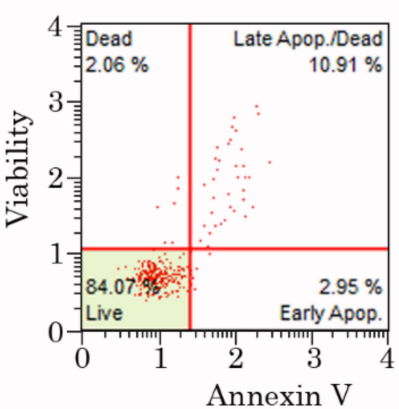

B.

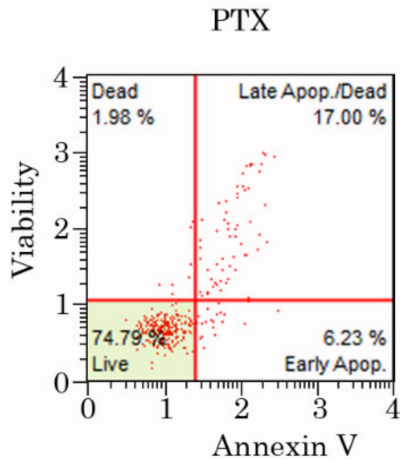

BGJ $398+$ PTX

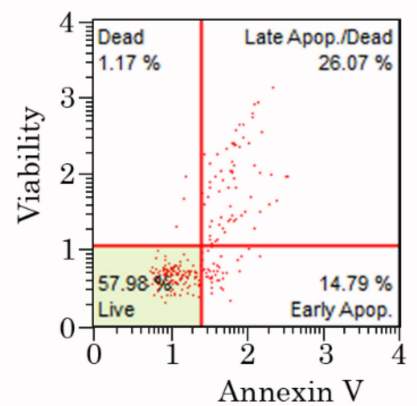

C.
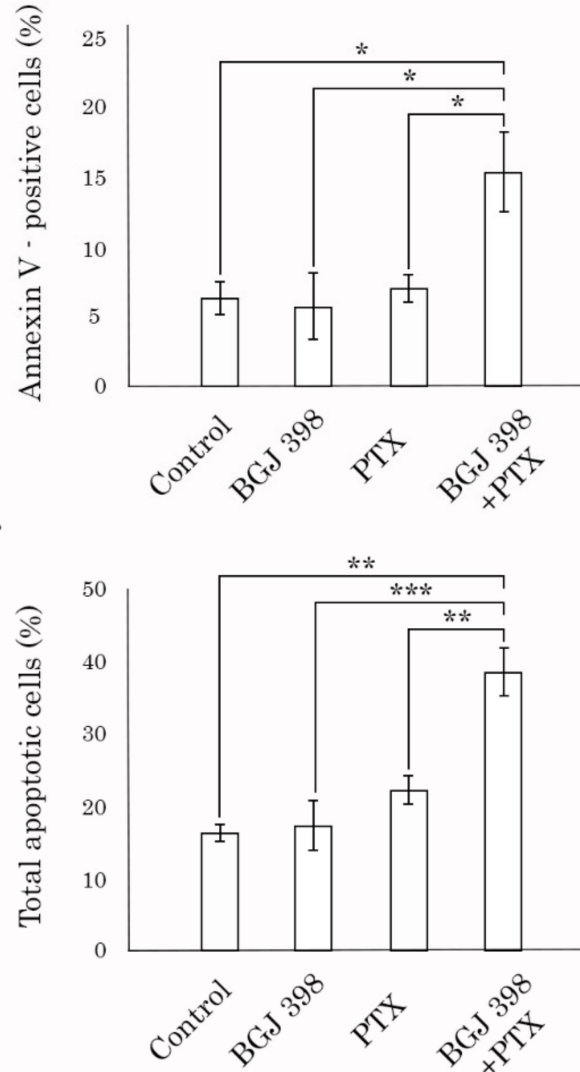

Figure 7. FACs analysis for apoptotic markers in Tx-R HCC 1806 breast cancer cells treated with DMSO (negative control), PTX $(1 \mu \mathrm{M}), \mathrm{BGJ} 398(1 \mu \mathrm{M})$ alone or in combination for $48 \mathrm{~h}$. (A) Representative dot-plot are shown. (B) Quantitative analysis of the early apoptotic cells after the treatment as indicated above. (C) Quantitative analysis of the total apoptotic cells after the treatment as indicated above. ${ }^{*} p<0.05,{ }^{* *} p<0.01,{ }^{* * *} p<0.001$.

An ability of BGJ 398 to sensitize cancer cells to PTX and Dox was also confirmed by the long-term viability assay and crystal violet staining. Neither BGJ 398 or PTX used alone inhibited proliferation and viability of HCC 1806-TxR cells, whereas the combination of these drugs provided significant anti-proliferative and cytotoxic effects (Figure 8A-middle panel). Densitometry analysis revealed a significant ( $\sim$-fold $)$ decrease in cell growth in HCC 1806-TxR cells treated with the combination of BGJ 398 and PTX when compared to the cells treated with BGJ 398 or PTX alone (Figure 8B). Similar results were obtained when TxR HCC 1806 cells were treated with Dox in presence of BGJ 398 (Figure 8A-middle panel). Quantification analysis also revealed the decrease of viability of Tx-R HCC 1806 treated with combination of Dox and BGJ 398, whereas these drugs used alone have no effect on cellular viability (Figure 8B). Similar data were obtained in GIST T-1 Tx-R cells. Again, BGJ 398 effectively re-sensitized these cells to PTX and Dox, whereas chemotherapeutic agents 
used alone failed to reduce their viability (Supplementary Figure S7), thereby revealing the MDR-associated phenotype in this particular cell subline. In contrast to BGJ 398, PD 173074 used alone or in combination with PTX or Dox have no inhibitory effects on the viability of Tx-R HCC 1806 cells (Figure 8A-bottom panel, and C). Of note, the anti-proliferative activities of BGJ 398 used in combination with PTX might be also due to the impairment of FGFR-signaling pathway, which was evidenced by the decrease of phosphorylated forms of FGFR1-2, adaptor protein FRS-2, and downstream signaling molecules, maintaining the cell survival and proliferation (STAT-1, 3 and S6) (Supplementary Figure S8).

A.
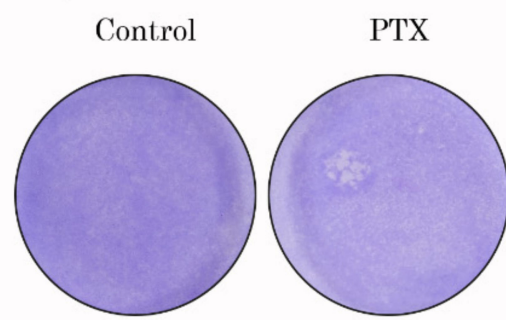

BGJ 398 + PTX
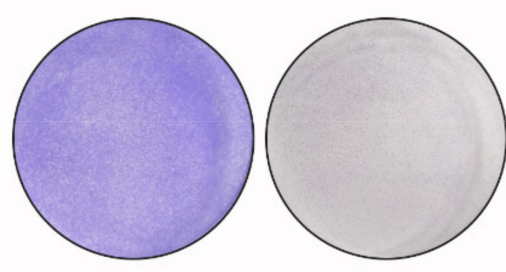

PD 173074

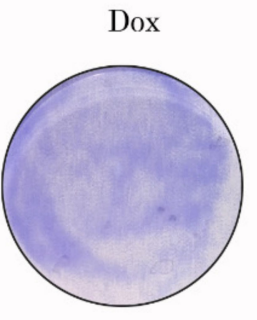

BGJ $398+$ Dox

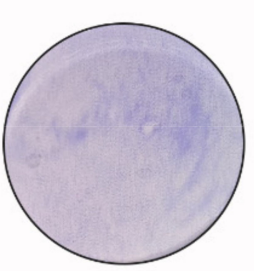

PD $173074+$ Dox
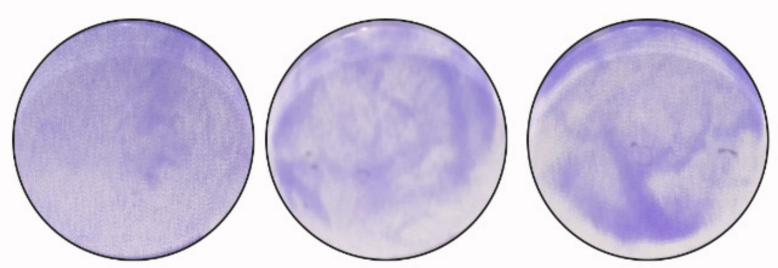

B.

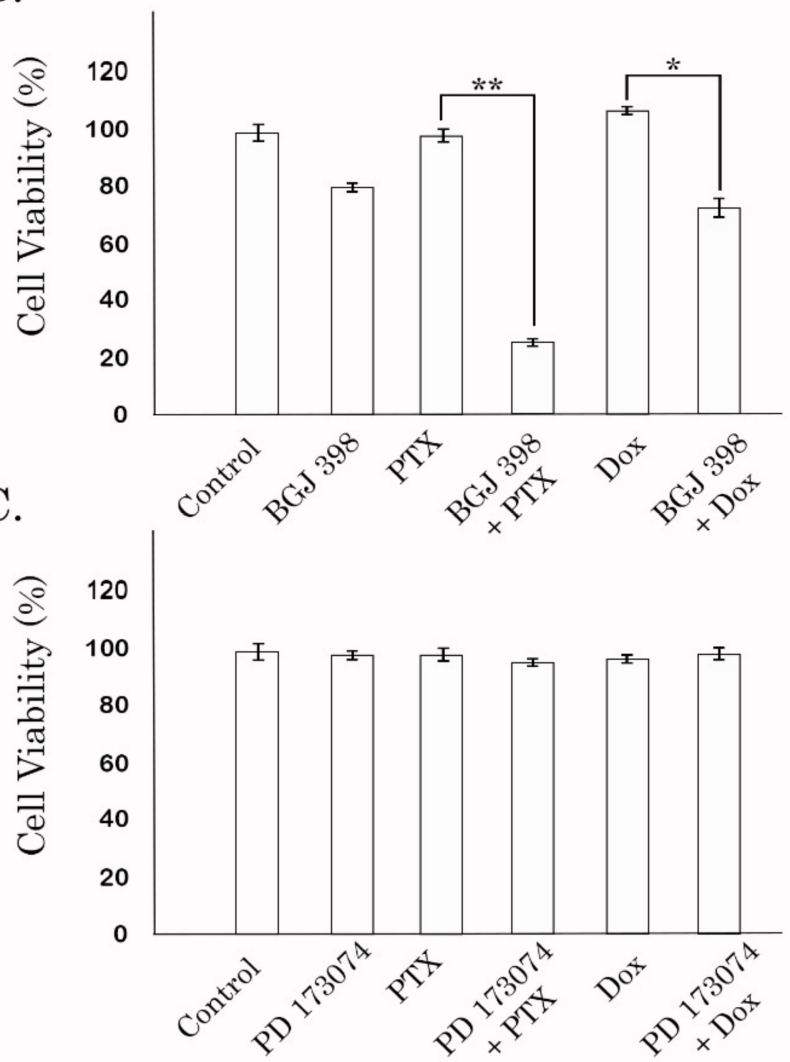

Figure 8. The impact of FGFR inhibitors (BGJ 398 and PD 173074) used in combination with PTX or Dox on proliferation and survival of Tx-R HCC 1806 breast cancer cells; (A) Crystal violet staining of Tx-R HCC 1806 cells that were treated with BGJ 398 (or PD 173074) alone or in combination with PTX (or Dox) for $96 \mathrm{~h}$. The cells treated with DMSO were used as a control. The cells treated with PTX or Dox alone illustrated chemoresistance of Tx-R HCC 1806 cells. The culture dishes were fixed with ice-cold 100\% methanol, stained with crystal violet, and photographed; (B) Quantification of crystal violet staining of Tx-R HCC 1806 cells treated with PTX and Dox alone or in combination with BGJ 398. The plates were dried, crystal violet was dissolved using $0.1 \%$ SDS solution, and absorbance was measured at $590 \mathrm{~nm}$. The graphs represent the mean $\pm \mathrm{SD}$. ${ }^{*} p<0.05 ;{ }^{* *} p<0.01$; (C) Quantification of crystal violet staining of Tx-R HCC 1806 cells treated with PTX and Dox alone or in combination with PD 173074.

The ability of BGJ 398 to re-sensitize Tx-R HCC 1806 cells to the chemotherapeutic agents (e.g., PTX and Dox) was also evidenced by an MTS-based colorimetric assay and calculated by using the R-package computational tool of the Synergy Finder program. The values of synergy between these drugs are shown in Table 2 and illustrates a prominent synergism of BGJ 398 and PTX for both Tx-R cell lines (e.g., HCC 1806 and GIST T-1) (Figure 9). High synergy scores were also observed between BGJ 398 and Dox for both 
Tx-R cell lines indicated above (Table 2). In contrast, PD 173074 failed to sensitize Tx-R cell sublines to PTX and Dox, as well (Table 2).

Table 2. Synergy scores between FGFR inhibitors and chemotherapeutic agents in Tx-R HCC 1806 and GIST T-1 cell lines.

\begin{tabular}{ccc}
\hline Chemical Compounds & HCC 1806 Tx-R & GIST T-1 Tx-R \\
\hline BGJ 398 + PTX & 11.12 & 28.22 \\
\hline BGJ 398 + Dox & 10.26 & 21.88 \\
\hline PD 173074 + PTX & 0.22 & 7.27 \\
\hline PD 173074 + Dox & 2.8 & 2.71 \\
\hline
\end{tabular}
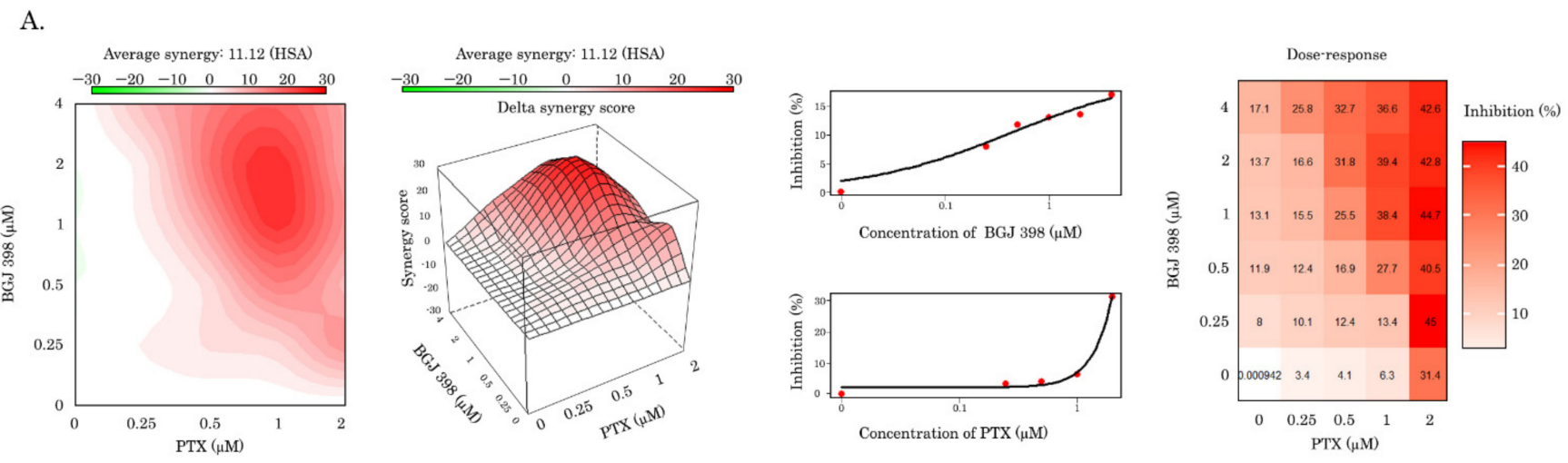

B.
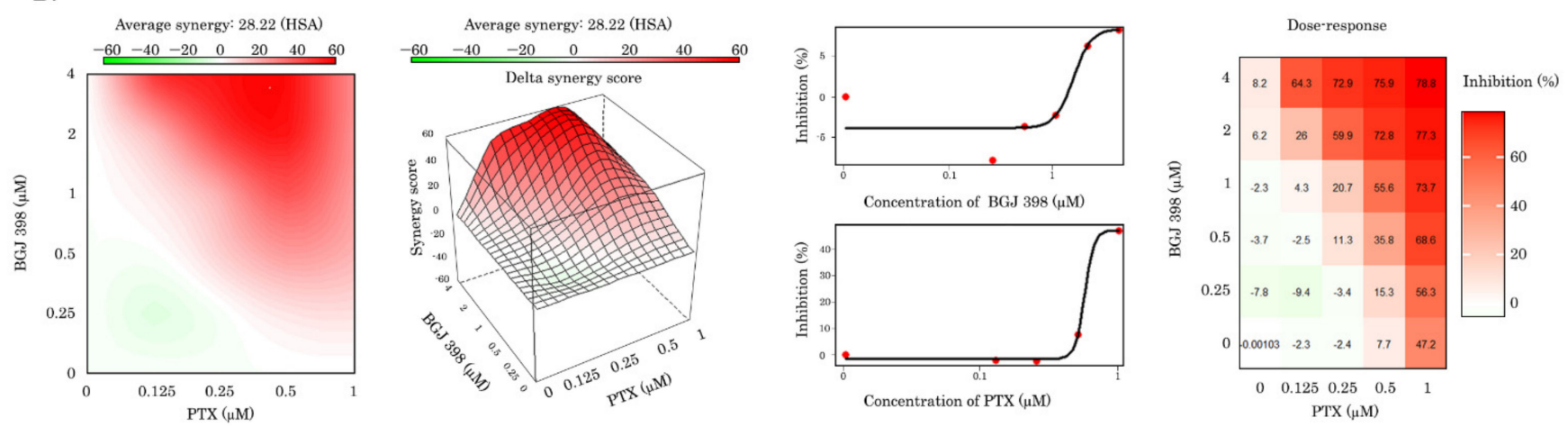

Figure 9. Assessment of the synergy between PTX and BGJ 398 in Tx-R HCC 1806 breast cancer (A) and GIST T-1 (B) cells. The average synergy for Tx-R HCC 1806 cells was 11.12, for GIST T-1 was 28.22 .

Previous studies demonstrated that reversal of MDR phenotype in cancer cells might be due to the lowered expression of the ABCB1 by the tested compound and was not due to the direct inhibition of P-gp transporter $[49,50]$. WB and PCR data shown in Figure 10 and Supplementary Table S2, respectively, illustrated no evidence of decrease of ABCB1 expression in BGJ 398-treated cells in both transcriptional and protein levels. Similarly, expression of the other ABC-transporters did not change after BGJ 398 treatment (Supplementary Table S2), thereby suggesting about BGJ 398's ability to sensitize MDRoverexpressing cancer cells to chemotherapeutic agents due to its interaction with this $\mathrm{ABC}$ transporter. 
A.

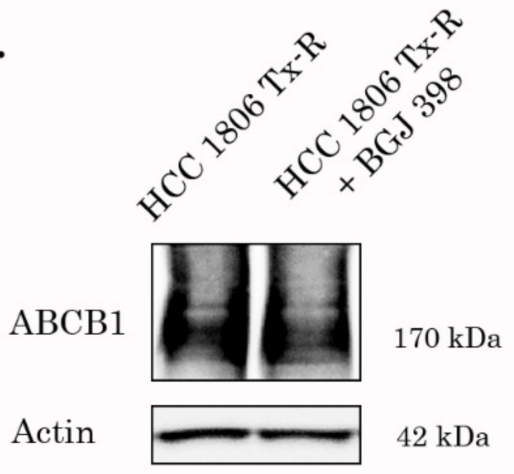

C.

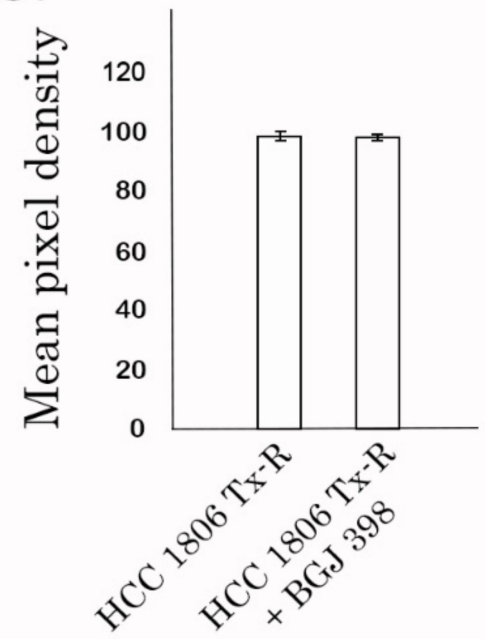

B.

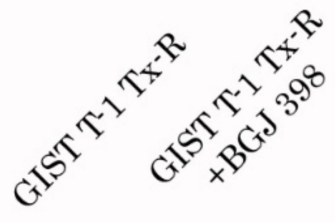

ABCB1

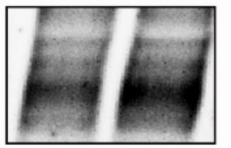

$170 \mathrm{kDa}$

Actin

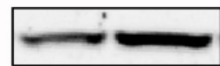

$42 \mathrm{kDa}$
D.

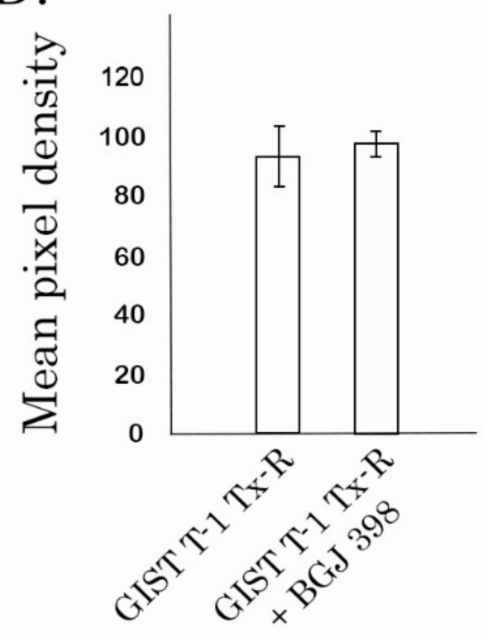

Figure 10. Expression of ABCB1 in Tx-R HCC 1806 (A) and GIST T-1 (B) cancer cells treated with DMSO (control) and BGJ398 for $72 \mathrm{~h}$. Actin stain was used as a loading control. Actin stain was used as a loading control. (C,D) Quantification by mean pixel density of ABCB1 in Tx-R HCC 1806 cells (C) and GIST T-1 (D) cancer cells after treatment as indicated above. Values are means \pm SD, $n=3$. Statistically significant differences were not observed.

This might be due to the overloading of its drug-binding pocket (DBP) or inhibiting ATPase activity via binding to the ATP-binding site of ABCB1. To delineate between these possibilities, molecular docking studies were performed (see below).

\subsection{Molecular Docking Analysis}

To determine the possible binding site of BGJ 398 in ABCB1, we performed a molecular docking analysis. Given that BGJ 398 effectively inhibited the efflux of chemotherapeutic agents (Dox and PTX) from MDR-expressing cancer cells, we examined the drug-binding pocket (DBP) of ABCB1 as a potential binding site for this ligand. Taking into account that BGJ 398 inhibits FGFR-signaling due to its binding to ATP-binding pocket, we also performed the molecular docking of this inhibitor with NBD1 (nucleotide-binding domain 1) of ABCB1. Molecular docking analysis was composed of 2 steps. First, we performed standard docking by using Glide XP mode and further utilized the Induced Fit Docking mode. Finally, to assess the sensitivity to input ligand geometry of the resulting induced-fit receptor conformation, we performed the re-docking of minimized ligands using Glide XP mode. Next, we calculated the RMSD values between the ligand poses obtained by induced-fit docking and re-docking procedure. Tariquidar, a well-known agent exhibiting a high binding affinity to the DBP of ABCB1, was used for the internal control.

Induced Fit Docking is a compromise solution between standard docking procedure and the molecular dynamics [46]. By using the standard virtual docking studies, the ligands 
are docked into the binding site of a receptor where the receptor is held rigid and the ligand is free to move. However, protein molecules do not behave as the rigid structures, and can undergo side-chain or back-bone movements, or both, as a result of the ligand binding. The Induced Fit Docking protocol allows to predict the changes in the receptor conformation upon the ligand binding, thereby reducing the percentage of false-negative results and predicting more accurate protein-ligand conformations when compared with the standard docking procedure [51].

The molecular docking data demonstrated the drug-binding pocket (DBP) of ABCB1 as the most possible binding site for BGJ 398 (Figure 11).

This data was obtained in standard docking XP mode and induced docking protocol, as well (Table 3). The low RMSD values for BGJ 398 and Tariquidar indicate the stability and low levels of the fluctuations in the ligand poses in DBP of ABCB1. Also, the low ligand strain energy values of BGJ 398 and Tariquidar in DBP illustrate the minimal energy required for the adaptation to the receptor-bound conformation compared to NBD1 of ABCB1. Unexcitingly, the similar rates of ligand strain energy values were observed for the other FGFR inhibitor PD 173074. This was in contrast with its inability to retain PTX and Dox in Tx-R cancer cells, as was shown in the Supplementary Figure S3 and Supplementary Figure S4. In addition, PD 173074 failed to re-sensitize Tx-R cancer cells to the chemotherapeutic agents PTX and Dox (Figure 8, Table 2). The possible explanations of these discrepancies are described in Discussion.

Table 3. Docking score (SP and XP Modes), MM-GBSA $\triangle$ Gbind prime energy, Ligand strain energy, RMSD of BGJ 398, Tariqiudar and PD 173074 with DBP and NBD1 of ABCB1.

\begin{tabular}{|c|c|c|c|c|c|}
\hline \multicolumn{6}{|c|}{ DBP of ABCB1 } \\
\hline \multicolumn{6}{|c|}{ BGJ398 } \\
\hline $\begin{array}{l}\text { Docking Type } \\
\text { Scoring Function }\end{array}$ & $\begin{array}{l}\text { Standart } \\
\text { Docking }\end{array}$ & $\begin{array}{l}\text { Induced Fit } \\
\text { Docking }\end{array}$ & RMSD & $\begin{array}{c}\text { MM-GBSA } \\
\Delta \mathrm{G}_{\text {bind }} \\
\text { (kcal/mol) }\end{array}$ & $\begin{array}{c}\text { Ligand Strain } \\
\text { Energy } \\
\text { (kcal/mol) }\end{array}$ \\
\hline Glide XP score & -5.866 & -9.605 & $1.74 \AA$ & -84.36 & 4.8 \\
\hline \multicolumn{6}{|c|}{ Tariquidar } \\
\hline Glide XP score & -7.249 & -10.100 & $3.2 \AA$ & -113.0 & 14.5 \\
\hline \multicolumn{6}{|c|}{ PD 173074} \\
\hline Glide XP score & -8.968 & -10.617 & $2.7 \AA$ & -101.2 & 6.2 \\
\hline \multicolumn{6}{|c|}{ NBD1 of ABCB1 } \\
\hline \multicolumn{6}{|c|}{ BGJ398 } \\
\hline $\begin{array}{l}\text { Docking Type } \\
\text { Scoring Function }\end{array}$ & $\begin{array}{l}\text { Standart } \\
\text { Docking }\end{array}$ & $\begin{array}{l}\text { Induced Fit } \\
\text { Docking }\end{array}$ & RMSD & $\begin{array}{c}\text { MM-GBSA } \\
\Delta \mathrm{G}_{\mathrm{bind}} \\
(\mathrm{kcal} / \mathrm{mol})\end{array}$ & $\begin{array}{c}\text { Energy } \\
\text { (kcal/mol) }\end{array}$ \\
\hline Glide XP score & -3.276 & -4.459 & $12.7 \AA$ & -58.7 & 10.4 \\
\hline \multicolumn{6}{|c|}{ Tariquidar } \\
\hline Glide XP score & -5.752 & -7.568 & $7.9 \AA$ & -79.4 & 18.6 \\
\hline \multicolumn{6}{|c|}{ PD 173074} \\
\hline Glide XP score & -5.147 & -6.257 & $5.2 \AA$ & -63.10 & 6.7 \\
\hline
\end{tabular}




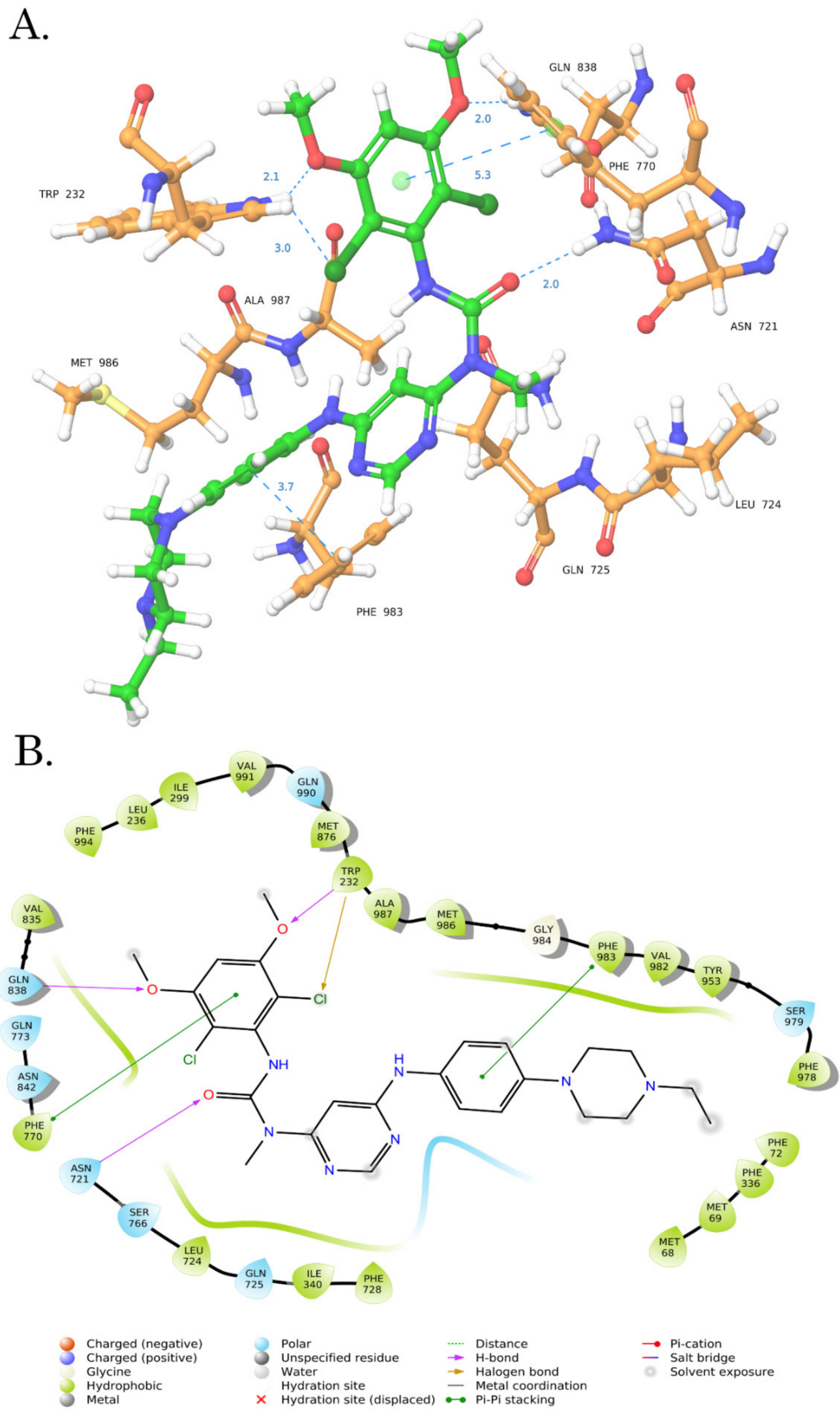

Figure 11. Computer modeling of BGJ 398 binding pose on DBP of ABCB1. (A) 3D diagram illustrating the proposed binding mode of the interactions of BGJ 398 with the ABCB1. (B) 2D Ligand interaction diagrams of the BGJ 398 with significant amino acid residues. 
Collectively, we show here for the first time the off-target effect of BGJ 398 on ABCB1overexpressing multi-drug resistant Tx-R cancer cells. This inhibitor of FGFR signaling effectively re-sensitized a broad spectrum of Tx-R cancer cells to certain chemotherapeutic agents (e.g., PTX and Dox) due to inhibition of their efflux from cancer cells. In contrast, PD 173074, the other inhibitor of FGFR1 signaling, failed to sensitize Tx-R cells to the Dox and PTX. This in turn correlated with inability of PD 173074 to retain PTX and Dox inside Tx-R cancer cells, therefore illustrating the novel off-target effect for BGJ 398 which is not associated with the inhibition of FGFR-signaling pathway.

\section{Discussion}

Despite significant progress in the development of novel chemotherapeutic agents exhibiting potent anti-tumor activities, the systemic adverse effects and rapid development of drug resistance remain the biggest challenges in current cancer therapies. Indeed, after initiation of anti-cancer therapy the tumors acquire resistance to the chemotherapeutic drugs via multiple mechanisms. These include activation of pathway-specific and/or non-specific mechanisms in tumor cells allowing them to escape from chemo- and targeted-based therapeutic agents. In particular, modification of the targeted enzyme or its downstream signaling molecules in tumors is considered as a major mechanism responsible for their acquired resistance to the tyrosine kinase inhibitors (TKIs) [52,53]. On the other side, DNA repair-deficient tumors that are initially responding well to the platinum compounds and/or poly (ADP-ribose) polymerase inhibitors develop resistance to these chemotherapeutic agents via restoration of the affected DNA repair pathway(s) [7]. In addition to the activation of tumor-specific pathways, cancer cells also develop non-specific mechanisms mediating their resistance to the DNA-damaging chemotherapeutic agents. This includes the activation of several biological modules, including an increased drug efflux resulting in multidrug resistance (MDR), inhibition of apoptosis, epithelial-mesenchymal transition, etc. The systemic and detailed analysis of the signaling pathways acquired tumor resistance to chemo- and targeted-based therapies are described in detail in the corresponding reviews [54,55].

Besides the well-known role of ABC-transporters in the efflux of the conventional anticancer agents from tumor cells, the emerging number of evidence demonstrates that MDR might also affect the anti-cancer activities of the tyrosine kinase inhibitors (TKIs). Indeed, ABCB1/Pgp/MDR1, ABCC1/MRP1, ABCC2/MRP2, and ABCG2/BCRP are involved in the development of resistance to TKIs. For example, ABCB1/P-gp/MDR1 was shown to facilitate the efflux of imatinib mesylate (IM) [56,57] and nilotinib [58] from cancer cells, thereby contributing to TKIs resistance. Similarly, imatinib [59,60], nilotinib [9], dasatinib [61], and danusertib [62] were found to be the substrates of ABCG2/BCRP transporter that increases the efflux of these TKIs from cancer cells. Finally, ABCC1/MRP1 was found as an effective transporter of imatinib from chronic myeloid leukemia (CML) cells [63], whereas sorafenib was proposed as a substrate for ABCC2/MRP2 [64], therefore causing sorafenib resistance of renal carcinoma cell lines in vitro. On the other hand, several TKIs have also been shown to inhibit the function of ABC-transporters, thereby interfering with drug efflux from cancer cells and providing an attractive therapeutic option to overcome MDR-related resistance to the conventional chemotherapeutic agents. For example, IM reversed the resistance to Dox in ABCB1-overexpressing cancer cells [65]. Similarly, IM restored the sensitivity of ABCG2-expressing cancer cells to topotecan via increasing the intracellular accumulation of this chemotherapeutic agent [66]. It was also reported that IM stimulated the ATP-ase activity in both ABCB1- and ABCG2-overexpressing cells, therefore indicating that RTKi acts as a substrate for both ABCB1 and ABCG2 [67]. Nilotinib, a second-generation of TKI, also inhibited the efflux function of ABCB1, ABCG2, and ABCC10 in cancer cells, thereby increasing the intracellular concentrations of the chemotherapeutic agents (e.g., PTX and doxorubicin) and potentiating their cytotoxic effects both in vitro and in vivo $[28,68]$. The ability of TKI's to interfere with the function of ABC-transporters was 
also shown for a broad spectrum of the inhibitors, including dasatinib [69], ponatinib [70], gefitinib [71], erlotinib [72], lapatinib [32], sunitinib [73,74], etc.

Despite the multiple reports illustrating the ability of TKIs to interfere with the function of MDR-related ABC-transporters, limited data is currently available about the potential role of the inhibitors of FGF-signaling to impair the function of these proteins and their abilities to re-sensitize cancer cells to the conventional chemotherapeutic agents.

Indeed, Chen Z-S with colleagues demonstrated that PD 173074, FGFR1 inhibitor, reversed ABCB1-mediated multidrug resistance to colchicine, PTX, and vinblastine (Vin) in colchicine-resistant human epidermoid carcinoma cell subline and $\mathrm{ABCB} 1$-overexpressing HEK293 cells, as well. This effect was due to the decreased active efflux of [3H]-PTX in ABCB1-overexpressing cells observed in efflux assay. Importantly, PD 173074 did not have the effect of ABCB1 expression but stimulated the ATP-ase activity of ABCB1 in a concentration-dependent manner, indicating a direct interaction with this transporter [75]. These effects of PD 173074 were further reproduced by using the MRP7-overexpressing HEK293 cells, thereby illustrating its ability to interfere with ABCC10 [41]. Of note, multiple reports illustrate that besides P-glycoprotein, expression of ABCC10/MRP7 (unlike other MRPs) also contributes to the resistance of various cancer cells to taxanes $[76,77]$ and can be utilized as a predictive biomarker for the resistance to PTX in several human malignancies, including a non-small cell lung cancer (NSCLC) [78], breast cancer [79] Strikingly, it was also shown that MRP7 can affect the in vivo tissue sensitivity to taxanes independently from ABCB1 [80].

Taken together, these findings suggest that modulation of $A B C B 1$ and $A B C C 10$ activities by specific and reversal inhibitors may have a significant clinical value in management of a broad spectrum of human malignancies that are treated with taxanes, based on action in eliminating these drugs from tumor tissues.

To overcome the ABC-mediated MDR mechanisms the reversal MDR inhibitors were generated. As mentioned before, first generation of ABCB1/MDR1/P-gp inhibitors included the calcium channel blocker verapamil, the sodium channel blocker quinidine and the immunosuppressant cyclosporine A. Despite of several promising trials illustrating an improvement of overall survival (OS) rates and increased remission in patients with Pgp-positive myelodysplastic syndromes receiving intensive chemotherapy combined with the first line inhibitors indicated above [20,81,82], most of the trials with first generation ABC-inhibitors showed no clinical benefits of these blockers and/or were terminated due to the toxicity reasons $[83,84]$. Second generation P-gp inhibitors, such as valspodar or PSC-833, and biricodar or VX-710 were later generated to improve the potency over the first-generation inhibitors and decrease toxicity. Despite valspodar fulfilled the requirement for a higher-affinity non-toxic Pgp inhibitor, the results of the majority of trials were also disappointing and did not show significant clinical benefits [85-88]. Moreover, valspodar exhibited the unanticipated pharmacokinetic interactions by interacting with cytochrome P450 3A4 and interfering with drug metabolism. As an outcome, anti-cancer drug exposure was increased leading to the overdose of cancer patients, which in turn raised the incidence and severity of adverse effects of anti-cancer therapies due to the decreased anti-cancer drug elimination [89]. Therefore, third-generation of low-toxic and potent ABC-inhibitors exhibiting minimal pharmacokinetic interactions were developed. This include tariquidar (XR9576), laniquidar (R101933), zosuquidar (LY335979) and CBT-1. Indeed, Phase I clinical trials of tariquidar used in combination with paclitaxel or doxorubicin showed no significant side effects and pharmacokinetic interactions [90]. However, the Phase III clinical studies aimed to examine the effectiveness of tariquidar with first-line chemotherapy for patients with NSCLC were terminated due to the toxicity reasons, as was reviewed in [24]. Zosuquidar was found as a potent and selective P-gp inhibitor and demonstrated clinical efficiency when used in combination with chemotherapeutic agents for limited set of the patients with acute myeloid leukemia (AML) [91]. Despite the clinical trials aimed to examine the potency of zosuquidar to ehsnace effectiveness of anti-cancer drugs for patents with AML and myelodysplastic syndromes are currently ongoing, the other trials did not 
show no significant difference in progression-free survival (PFS) and OS for the patients with metastatic or recurrent breast cancer [92].

Thus, it is an urgent need to develop novel, potent, selective and well-tolerated $\mathrm{ABC}$-inhibitors to enhance cytotoxicity of the chemotherapeutic agents during anti-cancer therapy. Alternatively, the activity of the well-known TKIs to inhibit the function of ABC transporters and therefore enhancing cytotoxic activities of anti-cancer agents have to be re-evaluated.

In the present study, we show for the first time that BGJ398, a potent and selective FGFR1-4 inhibitor, effectively sensitizes PTX-resistant TNBC cells to PTX. This was evidenced by a significant ( 24-fold) decrease of resistance index in both Tx-R HCC 1806 cells treated with PTX in presence of BGJ 398 (Table 1). Similar effects were obtained for another Tx-R cell subline- Tx-R GIST T-1 cell line, as well (Table 1). This point was also supported by a dramatic increase of apoptotic markers (e.g., cleaved PARP and caspase3 , increased numbers of Annexin V-positive cells, etc.) in PTX-resistant TNBCs treated with the combination of PTX and BGJ 398 (Figures 6 and 7, respectively) and was consistent with a high Synergy score $(>10)$ observed for all $\mathrm{Tx}-\mathrm{R}$ cancer cells treated with both compounds indicated above (Figure 9, Table 2). The aforementioned effects of BGJ 398 might be due to the impaired efflux of PTX from these cells, as was shown in Figures 2 and 3. In addition to PTX, the efflux of Dox was also impaired from Tx-R TNBC cells treated with BGJ 398, thereby confirming the ability of this FGFR inhibitor to abrogate the MDR phenotype of TNBC cells. Of note, similar to PD 173074 [75], BGJ 398 did not have an impact on ABCB1 expression in both transcriptional and protein levels (Figure 10, Supplementary Table S2), thereby suggesting BGJ 398's ability to inhibit the function of MDR-related ABC-transporters and, in particular, ABCB1. However, in contrast to the previous findings [41,75], PD 173074 failed to re-sensitize ABCB1-overexpressing HCC 1806 cancer cells to PTX and Dox (Figure 8, Supplementary Figure S6, Table 2). This was consistent with low potency of PD 173074 to retain chemotherapeutic drugs (e.g., Dox) inside Tx-R breast cancer and GIST T-1 cells (Supplementary Figure S3 and Supplementary Figure S4, respectively). In particular, this could be due to the low expression of MRP7 in the Tx-R cancer sublines (as shown in Supplementary Table S1) used in current study. In addition, we did not find the differences in binding energy scores between BG 398 and PD 173074, as shown in Table 3, thereby illustrating both of these FGFR inhibitors might interact evenly with DBP of ABCB1. Despite the fact that the binding energy of PD 173074 with $\mathrm{DBP}$ of $\mathrm{ABCB} 1$ is comparable to the binding energy of BGJ 398, further experiments are needed to prove this fact and determine the stability of the PD 173074 pose over time using various unbiased/biased molecular dynamics methods.

Of note, an ability of BGJ 398 to re-sensitize PTX-resistant cancer cells to PTX was not limited to the TNBC Tx-R cell lines. The similar effect of BGJ 398 was observed for ABCB1overexpressing gastrointestinal stromal tumor cells (GIST-T-1 Tx-R). Again, expression of apoptotic markers significantly increased when the cells indicated above were treated with combination of PTX and BGJ 398, when compared to the single treatment (Figure 6). Strikingly, we observed a prominent synergism for BGJ 398 and PTX for GIST Tx-R cells (Figure 9B), thereby illustrating high potency of BGJ 398 to restore sensitivity to PTX in Tx-R cancer cells exhibiting the different tissue origin. In contrast to BGJ 398, PD 173034 failed to re-sensitize GIST T-1 Tx-R cells to PTX (Figure 8 and Supplementary Figure S6). This was in agreement with the lack of the synergism between PD 173034 and PTX/Dox in Tx-R cell lines (e.g., Table 2).

Given that Tx-R cancer sublines utilized in the present study exhibited high expression levels of ABCB1, we also examined BGJ 398's ability to inhibit the activity of this ABC transporter. For this purpose, we utilized 2 fluorescent dyes known to be the substrates for ABCB1. For example, Calcein AM is known as a highly permeable MDR1 transporter substrate [93]. Similarly, Rhodamine 123, a member of the rhodamine family of fluorine dyes, also is commonly used to examine membrane transport by the ABCB1 gene product, MDR1 [94]. Indeed, our FACs data shown in Figure 4 illustrated that BGJ 398 significantly 
impaired the efflux of Calcein AM from Tx-R cancer cells, thereby providing the evidence of a molecular mechanism of BGJ 398-induced re-sensitization of TNBCs to PTX.

Given the BGJ 398 reversed sensitivity of ABCB1-overexpressing Tx-R cancer cells to PTX and Dox due to impaired efflux of these chemotherapeutic agents, we also examined its potential binding site in ABCB1. It was established that besides binding to membranebound and cytoplasmic tyrosine kinases, some of TKIs might also act as competitive inhibitors of $\mathrm{ABC}$ transporters by overloading the transporter's drug-binding pocket (DBP) [95]. Alternatively, some TKIs (e.g., afatinib) bind with the ATP-binding site of ABC transporters to inhibit their ATP-ase activity [96,97]. In addition, some TKIs down-regulate expression of ABC-transporters [95].

To delineate between these possibilities, we initially compared the expression of MDRrelated proteins between non-treated vs. BGJ 398-treated ABCB1-overexpressing cancer cells. As shown in Figure 10, BGJ 398 failed to decrease the expression of ABCB1 and other MDR-related proteins in both transcriptional and protein levels, therefore suggesting its ability to bind with $\mathrm{ABCB} 1$. The molecular docking data demonstrated the drug-binding pocket (DBP) of ABCB1 as the most possible binding site for BGJ 398 (Figure 11, Table 3). Indeed, despite BGJ 398 effectively binding to the ATP-binding pocket of FGFR2 to mediate its targeted activity, the affinity of this FGFR inhibitor to NBD of ABCB1 was significantly lower when compared with DBP (Table 3). This was evidenced by the data obtained by regular docking procedures and induced fit docking, as well. These differences might be due to two reasons. First, despite the functional similarities of ATP-binding sites of FGFR2 and ABCB1 (in both cases these sites mediate the ATP hydrolysis), the structures of ATP-binding sites in these molecules substantially differ from each other. For example, the ATP-binding site of NBD1 is phylogenetically more ancient and composed of highly conserved amino acid residues, also known as Walker A and Walker B motifs, as was discovered in 1982 [98]. In contrast, the ATP-binding site of tyrosine kinases domain is an evolutionally much younger protein-based domain that is mainly present in eukaryotic cells [99]. This domain is also composed of highly conserved motifs, such as Glycine-rich loop, HDR, DGF, etc. that substantially differ from Walker A and Walker B in ABCB1 (Supplementary Figure S9). Therefore, the significant differences in the structures of ATPbinding sites between $A B C B 1$ and FGFR2 might explain the low binding scores observed for BGJ 398 in the ATP-binding site of NBD1. Second, DBP of ABCB1 interacts with the chemotherapeutic agents via several flexible alpha spirals, directed to the top of the inward-facing conformation $[100,101]$. Based on such flexibility of the alpha spirals in ABCB1, binding of BGJ 398 with a flexible transmembrane site is much more probable, when compared with the stable and highly conserved ATP-binding site of NBD1.

This data is consistent with the previous findings that illustrated the possibility to inhibit ABCB1 activity by the RTKis. Indeed, besides BGJ 398, IM was also shown to bind with the transmembrane domain, but not with NBD of ABCB1 [67]. Similar activities were recently found for FGFR1 inhibitor, PD 173074 [41]. The RTKis indicated above significantly increased ATP-ase activity of ABCB1, thereby indicating the ability to bind with a drug-binding pocket of $\mathrm{ABCB} 1$.

Taken together, this data suggests the interaction of BGJ 398 with the amino acids of a drug-binding pocket of $\mathrm{ABCB} 1$ and is consistent with recent findings indicated above. Further experiments by using advanced methods (e.g., unbiased/biased molecular dynamics, FEP calculation, $\mathrm{X}$-ray diffraction, or Cryo-EM) will be helpful to illustrate the precise pose of the BGJ 398 and its potential interactions with the transmembrane domain of ABCB1.

Collectively, we show here that BGJ 398, a selective FGFR1-4 inhibitor, inhibits the efflux function of the ABCB1 transporter and effectively re-sensitizes MDR-expressing cancer cells to certain chemotherapeutic agents, including PTX and Dox. Our current data is in close consistency with recent findings of $\mathrm{Wu} \mathrm{S}$ with co-authors, illustrating a high potency of erdafitinib, a small-molecule pan-FGFR kinase inhibitor to induce sensitization of ABCB1-overexpressing cancer cell lines to certain chemotherapeutic drugs, including PTX, vincristine, and topotecan [102]. It was also found that erdafitinib stimulates ATPase 
activity in ABCB1-expressing cells, thereby indicating that this RTKi acts like a substrate for ABCB1. Moreover, study from Kim SH et al. showed that PTX used in combination with BGJ 398 synergistically suppressed urothelial carcinoma cell migration and colony formation via regulation of EMT-associated factors, while FGFR1 knockdown enhanced the antitumor effect of PTX [103]. This in turn suggests that BGJ 398 might be considered as a potent RTKi to enhance cytotoxic activities of anti-cancer agents for ABCB1-overexpresing human malignancies, whereas high levels of ABCB1 in tumor tissues could be further evaluated as a biomarker for treatment selection of BGJ 398 and PTX.

Taking into account that acquired resistance to the conventional chemotherapies in TNBC is commonly associated with the development of MDR phenotype after initiation of the chemotherapy, our data illustrate the BGJ 398 (infigratinib) as a potential therapeutic option for MDR-related TNBCs, especially for the subset of patients with TNBCs harboring FGFR alterations. Indeed, activation of FGFR-signaling pathway in breast cancer was evidenced by the multiple studies [104,105], and analyzed in detail in several recent reviews to illustrate the role of FGFR signaling in breast cancer pathogenesis and progression [106] and provide the molecular basis for ongoing clinical trials [ClinicalTrials.gov Identifier: NCT02365597]. Moreover, our recent data demonstrated activation of FGFR-signaling in GIST might be an alternative mechanism of secondary resistance to IM [107] and therefore serve as an attractive molecular target to re-sensitize GIST to IM both in vitro and in vivo [108]. Besides the BGJ 398-induced impairment of ABCB1 function shown here, we recently demonstrated an ability of this RTKi to sensitize cancer cells to topoisomerase II inhibitors (e.g., doxorubicin) via attenuation of homology-mediated DNA repair [109], thereby illustrating the complex mechanism of BGJ 398-induced sensitization of cancer cells to the chemotherapeutic agents.

Supplementary Materials: The following supporting information can be downloaded at: https: / / www.mdpi.com/article/10.3390/biomedicines10030601/s1, Figure S1: Fluorescence microscopy and FACs analysis of the intracellular accumulation of doxorubicin (DOX) in Tx-R GIST T-1 cells; Figure S2: The intracellular accumulation of Dox in drug-sensitive parental HCC 1806 cells and Tx-R HCC 1806 cells; Figure S3: Fluorescence microscopy analysis of the intracellular accumulation of doxorubicin (DOX) in Tx-R HCC 1806 breast cancer and GIST T-1 cells; Figure S4: Morphological changes in Tx-R HCC 1806 breast cancer cells and GIST T-1 cells. Figure S5: BGJ 398 potentiates apoptosis of Tx-R GIST T-1 cells treated with combination of PTX (or Dox). Figure S6: FACs analysis for apoptotic markers in Tx-R HCC 1806 breast cancer cells treated with PD 173074 and PTX (or Dox) alone or in combination. Figure S7: The impact of BGJ 398 used in combination with PTX or Dox on proliferation and survival of Tx-R GIST T-1 cells. Figure S8: Expression of the markers of FGFRsignaling in naïve and Tx-R HCC 1806 cells. Figure S9: 3D structure comparison of ATP-binding sites of FGFR2 and ABCB1. Table S1: Fold-increase of ABC-transporters mRNA levels in Tx-R cancer cells compared with the parental cells. Table S2: Fold-decrease of ABC-transporters mRNA levels in BGJ 398-treated Tx-R cancer cells compared with non-treated Tx-R cells.

Author Contributions: Conceptualization, S.B.; methodology, S.B., P.D., S.M., K.S., E.V., F.B., A.G. and I.M.; software, S.B., P.D., S.M., K.S., E.V., F.B., A.G. and I.M.; validation, S.B., A.G. and I.M.; formal analysis, S.B., P.D., S.M., K.S., E.V., F.B., A.G. and I.M.; investigation, S.B., P.D., S.M., K.S., E.V., F.B., A.G. and I.M.; resources, S.B.; data curation, S.B., P.D., S.M., K.S., F.B., A.G. and I.M.; writing-S.B., S.M., K.S., F.B. and A.G.; original draft preparation, S.B.; writing-S.B.; visualization, S.B.; supervision, S.B.; project administration, S.B.; funding acquisition, S.B. All authors have read and agreed to the published version of the manuscript.

Funding: This study was supported by a Russian Foundation for Basic Research (RFBR) (grant no. 20-015-00034A).

Institutional Review Board Statement: Not available.

Informed Consent Statement: The research was performed solely on the mammalian cell lines (informed consent and animals statement are not required).

Data Availability Statement: Not available. 
Conflicts of Interest: The authors declare that they have no competing financial interest.

\section{References}

1. Hersey, P.; Zhang, X.D.; Mhaidat, N. Overcoming Resistance to Apoptosis in Cancer Therapy. Adv. Exp. Med. Biol. 2008, 615, 105-126. [CrossRef] [PubMed]

2. Borst, P. Cancer Drug Pan-Resistance: Pumps, Cancer Stem Cells, Quiescence, Epithelial to Mesenchymal Transition, Blocked Cell Death Pathways, Persisters or What? Open Biol. 2012, 2, 120066. [CrossRef] [PubMed]

3. Viktorsson, K.; Lewensohn, R.; Zhivotovsky, B. Apoptotic Pathways and Therapy Resistance in Human Malignancies. Adv. Cancer Res. 2005, 94, 143-196. [CrossRef] [PubMed]

4. Zheng, X.; Carstens, J.L.; Kim, J.; Scheible, M.; Kaye, J.; Sugimoto, H.; Wu, C.-C.; LeBleu, V.S.; Kalluri, R. Epithelial-to-Mesenchymal Transition Is Dispensable for Metastasis but Induces Chemoresistance in Pancreatic Cancer. Nature 2015, 527, 525-530. [CrossRef]

5. Du, B.; Shim, J.S. Targeting Epithelial-Mesenchymal Transition (EMT) to Overcome Drug Resistance in Cancer. Molecules 2016, 21, 965. [CrossRef]

6. $\quad$ Fischer, K.R.; Durrans, A.; Lee, S.; Sheng, J.; Li, F.; Wong, S.T.C.; Choi, H.; El Rayes, T.; Ryu, S.; Troeger, J.; et al. Epithelial-toMesenchymal Transition Is Not Required for Lung Metastasis but Contributes to Chemoresistance. Nature 2015, 527, $472-476$. [CrossRef]

7. Lord, C.J.; Ashworth, A. Mechanisms of Resistance to Therapies Targeting BRCA-Mutant Cancers. Nat. Med. 2013, 19, 1381-1388. [CrossRef]

8. Szakács, G.; Paterson, J.K.; Ludwig, J.A.; Booth-Genthe, C.; Gottesman, M.M. Targeting Multidrug Resistance in Cancer. Nat. Rev. Drug Discov. 2006, 5, 219-234. [CrossRef]

9. Hegedus, C.; Ozvegy-Laczka, C.; Apáti, A.; Magócsi, M.; Német, K.; Orfi, L.; Kéri, G.; Katona, M.; Takáts, Z.; Váradi, A.; et al. Interaction of Nilotinib, Dasatinib and Bosutinib with ABCB1 and ABCG2: Implications for Altered Anti-Cancer Effects and Pharmacological Properties. Br. J. Pharmacol. 2009, 158, 1153-1164. [CrossRef]

10. Dohse, M.; Robey, R.W.; Brendel, C.; Bates, S.; Neubauer, A.; Scharenberg, C. Efflux of the Tyrosine Kinase Inhibitors Imatinib and Nilotinib (AMN107) Is Mediated by ABCB1 (MDR1)-Type P-Glycoprotein. Blood 2006, 108, 1367. [CrossRef]

11. Chen, Z.-S.; Robey, R.W.; Belinsky, M.G.; Shchaveleva, I.; Ren, X.-Q.; Sugimoto, Y.; Ross, D.D.; Bates, S.E.; Kruh, G.D. Transport of Methotrexate, Methotrexate Polyglutamates, and 17 $\beta$-Estradiol 17-( $\beta$-d-Glucuronide) by ABCG2: Effects of Acquired Mutations at R482 on Methotrexate Transport1. Cancer Res. 2003, 63, 4048-4054.

12. Austin Doyle, L.; Ross, D.D. Multidrug Resistance Mediated by the Breast Cancer Resistance Protein BCRP (ABCG2). Oncogene 2003, 22, 7340-7358. [CrossRef] [PubMed]

13. Sodani, K.; Patel, A.; Kathawala, R.J.; Chen, Z.-S. Multidrug Resistance Associated Proteins in Multidrug Resistance. Chin. J. Cancer 2012, 31, 58-72. [CrossRef]

14. Kruh, G.D.; Belinsky, M.G. The MRP Family of Drug Efflux Pumps. Oncogene 2003, 22, 7537-7552. [CrossRef]

15. Gottesman, M.M. Mechanisms of Cancer Drug Resistance. Annu. Rev. Med. 2002, 53, 615-627. [CrossRef] [PubMed]

16. Cole, S.P.C. Targeting Multidrug Resistance Protein 1 (MRP1, ABCC1): Past, Present, and Future. Annu. Rev. Pharmacol. Toxicol. 2014, 54, 95-117. [CrossRef] [PubMed]

17. Binkhathlan, Z.; Lavasanifar, A. P-Glycoprotein Inhibition as a Therapeutic Approach for Overcoming Multidrug Resistance in Cancer: Current Status and Future Perspectives. Curr. Cancer Drug Targets 2013, 13, 326-346. [CrossRef]

18. Palmeira, A.; Sousa, E.; Vasconcelos, M.H.; Pinto, M.M. Three Decades of P-Gp Inhibitors: Skimming through Several Generations and Scaffolds. Curr. Med. Chem. 2012, 19, 1946-2025. [CrossRef] [PubMed]

19. Silva, R.; Vilas-Boas, V.; Carmo, H.; Dinis-Oliveira, R.J.; Carvalho, F.; de Lourdes Bastos, M.; Remião, F. Modulation of PGlycoprotein Efflux Pump: Induction and Activation as a Therapeutic Strategy. Pharmacol. Ther. 2015, 149, 1-123. [CrossRef] [PubMed]

20. List, A.F.; Kopecky, K.J.; Willman, C.L.; Head, D.R.; Persons, D.L.; Slovak, M.L.; Dorr, R.; Karanes, C.; Hynes, H.E.; Doroshow, J.H.; et al. Benefit of Cyclosporine Modulation of Drug Resistance in Patients with Poor-Risk Acute Myeloid Leukemia: A Southwest Oncology Group Study. Blood 2001, 98, 3212-3220. [CrossRef]

21. Rowinsky, E.K.; Smith, L.; Wang, Y.M.; Chaturvedi, P.; Villalona, M.; Campbell, E.; Aylesworth, C.; Eckhardt, S.G.; Hammond, L.; Kraynak, M.; et al. Phase I and Pharmacokinetic Study of Paclitaxel in Combination with Biricodar, a Novel Agent That Reverses Multidrug Resistance Conferred by Overexpression of Both MDR1 and MRP. J. Clin. Oncol. 1998, 16, 2964-2976. [CrossRef]

22. Wilson, W.H.; Jamis-Dow, C.; Bryant, G.; Balis, F.M.; Klecker, R.W.; Bates, S.E.; Chabner, B.A.; Steinberg, S.M.; Kohler, D.R.; Wittes, R.E. Phase I and Pharmacokinetic Study of the Multidrug Resistance Modulator Dexverapamil with EPOCH Chemotherapy. J. Clin. Oncol. 1995, 13, 1985-1994. [CrossRef]

23. Fox, E.; Widemann, B.C.; Pastakia, D.; Chen, C.C.; Yang, S.X.; Cole, D.; Balis, F.M. Pharmacokinetic and Pharmacodynamic Study of Tariquidar (XR9576), a P-Glycoprotein Inhibitor, in Combination with Doxorubicin, Vinorelbine, or Docetaxel in Children and Adolescents with Refractory Solid Tumors. Cancer Chemother. Pharmacol. 2015, 76, 1273-1283. [CrossRef]

24. Tamaki, A.; Ierano, C.; Szakacs, G.; Robey, R.W.; Bates, S.E. The Controversial Role of ABC Transporters in Clinical Oncology. Essays Biochem. 2011, 50, 209-232. [CrossRef] 
25. Cripe, L.D.; Uno, H.; Paietta, E.M.; Litzow, M.R.; Ketterling, R.P.; Bennett, J.M.; Rowe, J.M.; Lazarus, H.M.; Luger, S.; Tallman, M.S. Zosuquidar, a Novel Modulator of P-Glycoprotein, Does Not Improve the Outcome of Older Patients with Newly Diagnosed Acute Myeloid Leukemia: A Randomized, Placebo-Controlled Trial of the Eastern Cooperative Oncology Group 3999. Blood 2010, 116, 4077-4085. [CrossRef] [PubMed]

26. Stefan, S.M. Multi-Target ABC Transporter Modulators: What next and Where to Go? Future Med. Chem. 2019, 11, 2353-2358. [CrossRef] [PubMed]

27. Robey, R.W.; Pluchino, K.M.; Hall, M.D.; Fojo, A.T.; Bates, S.E.; Gottesman, M.M. Revisiting the Role of ABC Transporters in Multidrug-Resistant Cancer. Nat. Rev. Cancer 2018, 18, 452-464. [CrossRef]

28. Tiwari, A.K.; Sodani, K.; Wang, S.-R.; Kuang, Y.-H.; Ashby, C.R.J.; Chen, X.; Chen, Z.-S. Nilotinib (AMN107, Tasigna) Reverses Multidrug Resistance by Inhibiting the Activity of the ABCB1/Pgp and ABCG2/BCRP/MXR Transporters. Biochem. Pharmacol. 2009, 78, 153-161. [CrossRef]

29. Shen, T.; Kuang, Y.-H.; Ashby, C.R.; Lei, Y.; Chen, A.; Zhou, Y.; Chen, X.; Tiwari, A.K.; Hopper-Borge, E.; Ouyang, J.; et al. Imatinib and Nilotinib Reverse Multidrug Resistance in Cancer Cells by Inhibiting the Efflux Activity of the MRP7 (ABCC10). PLoS ONE 2009, 4, e7520. [CrossRef]

30. Tong, X.; Wang, F.; Liang, S.; Zhang, X.; He, J.; Chen, X.-G.; Liang, Y.; Mi, Y.; To, K.K.W.; Fu, L. Apatinib (YN968D1) Enhances the Efficacy of Conventional Chemotherapeutical Drugs in Side Population Cells and ABCB1-Overexpressing Leukemia Cells. Biochem. Pharmacol. 2012, 83, 586-597. [CrossRef] [PubMed]

31. Mi, Y.; Liang, Y.; Huang, H.; Zhao, H.; Wu, C.-P.; Wang, F.; Tao, L.; Zhang, C.; Dai, C.-L.; Tiwari, A.K.; et al. Apatinib (YN968D1) Reverses Multidrug Resistance by Inhibiting the Efflux Function of Multiple ATP-Binding Cassette Transporters. Cancer Res. 2010, 70, 7981-7991. [CrossRef]

32. Dai, C.; Tiwari, A.K.; Tiwari, A.K.; Wu, C.-P.; Su, X.-D.; Wang, S.-R.; Liu, D.; Ashby, C.R.; Huang, Y.; Robey, R.W.; et al. Lapatinib (Tykerb, GW572016) Reverses Multidrug Resistance in Cancer Cells by Inhibiting the Activity of ATP-Binding Cassette Subfamily B Member 1 and G Member 2. Cancer Res. 2008, 68, 7905-7914. [CrossRef] [PubMed]

33. Furuse, J.; Goyal, L.; Meric-Bernstam, F.; Hollebecque, A.; Valle, J.W.; Morizane, C.; Karasic, T.B.; Abrams, T.A.; Kelley, R.K.; Cassier, P.A.; et al. 116MO Efficacy, Safety, and Quality of Life (QoL) with Futibatinib in Patients (Pts) with Intrahepatic Cholangiocarcinoma (ICCA) Harboring FGFR2 Fusions/Rearrangements: FOENIX-CCA2. Ann. Oncol. 2020, 31, S1288-S1289. [CrossRef]

34. Abou-Alfa, G.K.; Sahai, V.; Hollebecque, A.; Vaccaro, G.; Melisi, D.; Al-Rajabi, R.; Paulson, A.S.; Borad, M.J.; Gallinson, D.; Murphy, A.G.; et al. Pemigatinib for Previously Treated, Locally Advanced or Metastatic Cholangiocarcinoma: A Multicentre, Open-Label, Phase 2 Study. Lancet Oncol. 2020, 21, 671-684. [CrossRef]

35. Javle, M.; Lowery, M.; Shroff, R.T.; Weiss, K.H.; Springfeld, C.; Borad, M.J.; Ramanathan, R.K.; Goyal, L.; Sadeghi, S.; Macarulla, T.; et al. Phase II Study of BGJ398 in Patients With FGFR-Altered Advanced Cholangiocarcinoma. J. Clin. Oncol. 2018, 36, 276-282. [CrossRef] [PubMed]

36. Loriot, Y.; Necchi, A.; Park, S.H.; Garcia-Donas, J.; Huddart, R.; Burgess, E.; Fleming, M.; Rezazadeh, A.; Mellado, B.; Varlamov, S.; et al. Erdafitinib in Locally Advanced or Metastatic Urothelial Carcinoma. N. Engl. J. Med. 2019, 381, 338-348. [CrossRef]

37. Sharpe, R.; Pearson, A.; Herrera-Abreu, M.T.; Johnson, D.; Mackay, A.; Welti, J.C.; Natrajan, R.; Reynolds, A.R.; Reis-Filho, J.S.; Ashworth, A.; et al. FGFR Signaling Promotes the Growth of Triple-Negative and Basal-Like Breast Cancer Cell Lines Both In Vitro and In Vivo. Clin. Cancer Res. 2011, 17, 5275-5286. [CrossRef]

38. Cunningham, D.L.; Sarhan, A.R.; Creese, A.J.; Larkins, K.P.B.; Zhao, H.; Ferguson, H.R.; Brookes, K.; Marusiak, A.A.; Cooper, H.J.; Heath, J.K. Differential Responses to Kinase Inhibition in FGFR2-Addicted Triple Negative Breast Cancer Cells: A Quantitative Phosphoproteomics Study. Sci. Rep. 2020, 10, 7950. [CrossRef]

39. Yee, D. Insulin-like Growth Factor Receptor Inhibitors: Baby or the Bathwater? J. Natl. Cancer Inst. 2012, 104, 975-981. [CrossRef]

40. Jafarian, A.H.; Kooshkiforooshani, M.; Farzad, F.; Mohamadian Roshan, N. The Relationship Between Fibroblastic Growth Factor Receptor-1 (FGFR1) Gene Amplification in Triple Negative Breast Carcinomas and Clinicopathological Prognostic Factors. Iran. J. Pathol. 2019, 14, 299-304. [CrossRef]

41. Patel, A.; Tiwari, A.K.; Chufan, E.E.; Sodani, K.; Anreddy, N.; Singh, S.; Ambudkar, S.V.; Stephani, R.; Chen, Z.-S. PD173074, a Selective FGFR Inhibitor, Reverses ABCB1-Mediated Drug Resistance in Cancer Cells. Cancer Chemother. Pharmacol. 2013, 72, 189-199. [CrossRef]

42. Boichuk, S.; Galembikova, A.; Sitenkov, A.; Khusnutdinov, R.; Dunaev, P.; Valeeva, E.; Usolova, N. Establishment and Characterization of a Triple Negative Basal-like Breast Cancer Cell Line with Multi-Drug Resistance. Oncol. Lett. 2017, 14, 5039-5045. [CrossRef] [PubMed]

43. Khusnutdinov, R.; Galembikova, A.R.; Boichuk, S. Establishment of the Clone of Gastrointestinal Stromal Tumor Cells with the Signs of Multiple Drug Resistance and Assessment of Its Properties. Sovrem. Tehnol. Med. 2016, 8, 36-41. [CrossRef]

44. Taguchi, T.; Sonobe, H.; Toyonaga, S.; Yamasaki, I.; Shuin, T.; Takano, A.; Araki, K.; Akimaru, K.; Yuri, K. Conventional and Molecular Cytogenetic Characterization of a New Human Cell Line, GIST-T1, Established from Gastrointestinal Stromal Tumor. Lab. Investig. 2002, 82, 663-665. [CrossRef]

45. Livak, K.J.; Schmittgen, T.D. Analysis of Relative Gene Expression Data Using Real-Time Quantitative PCR and the $2^{-\Delta \Delta C T}$ Method. Methods 2001, 25, 402-408. [CrossRef] 
46. Sherman, W.; Day, T.; Jacobson, M.P.; Friesner, R.A.; Farid, R. Novel Procedure for Modeling Ligand/Receptor Induced Fit Effects. J. Med. Chem. 2006, 49, 534-553. [CrossRef] [PubMed]

47. Li, J.; Abel, R.; Zhu, K.; Cao, Y.; Zhao, S.; Friesner, R.A. The VSGB 2.0 Model: A next Generation Energy Model for High Resolution Protein Structure Modeling. Proteins Struct. Funct. Bioinform. 2011, 79, 2794-2812. [CrossRef] [PubMed]

48. Yadav, B.; Wennerberg, K.; Aittokallio, T.; Tang, J. Searching for Drug Synergy in Complex Dose-Response Landscapes Using an Interaction Potency Model. Comput. Struct. Biotechnol. J. 2015, 13, 504-513. [CrossRef] [PubMed]

49. Shin, S.Y.; Choi, B.H.; Kim, J.-R.; Kim, J.-H.; Lee, Y.H. Suppression of P-Glycoprotein Expression by Antipsychotics Trifluoperazine in Adriamycin-Resistant L1210 Mouse Leukemia Cells. Eur. J. Pharm. Sci. 2006, 28, 300-306. [CrossRef]

50. Choi, B.H.; Kim, C.G.; Lim, Y.; Shin, S.Y.; Lee, Y.H. Curcumin Down-Regulates the Multidrug-Resistance Mdr1b Gene by Inhibiting the PI3K/Akt/NFKB Pathway. Cancer Lett. 2008, 259, 111-118. [CrossRef]

51. Lokwani, D.K.; Sarkate, A.P.; Karnik, K.S.; Nikalje, A.P.G.; Seijas, J.A. Structure-Based Site of Metabolism (SOM) Prediction of Ligand for CYP3A4 Enzyme: Comparison of Glide XP and Induced Fit Docking (IFD). Molecules 2020, 25, 1622. [CrossRef] [PubMed]

52. Gainor, J.F.; Shaw, A.T. Emerging Paradigms in the Development of Resistance to Tyrosine Kinase Inhibitors in Lung Cancer. J. Clin. Oncol. Off. J. Am. Soc. Clin. Oncol. 2013, 31, 3987-3996. [CrossRef] [PubMed]

53. Sharma, G.G.; Mota, I.; Mologni, L.; Patrucco, E.; Gambacorti-Passerini, C.; Chiarle, R. Tumor Resistance against ALK Targeted Therapy-Where It Comes From and Where It Goes. Cancers 2018, 10, 62. [CrossRef]

54. Aleksakhina, S.N.; Kashyap, A.; Imyanitov, E.N. Mechanisms of Acquired Tumor Drug Resistance. Biochim. Biophys. Acta Rev. Cancer 2019, 1872, 188310. [CrossRef] [PubMed]

55. Sabnis, A.J.; Bivona, T.G. Principles of Resistance to Targeted Cancer Therapy: Lessons from Basic and Translational Cancer Biology. Trends Mol. Med. 2019, 25, 185-197. [CrossRef]

56. Mahon, F.-X.; Belloc, F.; Lagarde, V.; Chollet, C.; Moreau-Gaudry, F.; Reiffers, J.; Goldman, J.M.; Melo, J. V MDR1 Gene Overexpression Confers Resistance to Imatinib Mesylate in Leukemia Cell Line Models. Blood 2003, 101, 2368-2373. [CrossRef]

57. Illmer, T.; Schaich, M.; Platzbecker, U.; Freiberg-Richter, J.; Oelschlägel, U.; von Bonin, M.; Pursche, S.; Bergemann, T.; Ehninger, G.; Schleyer, E. P-Glycoprotein-Mediated Drug Efflux Is a Resistance Mechanism of Chronic Myelogenous Leukemia Cells to Treatment with Imatinib Mesylate. Leukemia 2004, 18, 401-408. [CrossRef]

58. Mahon, F.-X.; Hayette, S.; Lagarde, V.; Belloc, F.; Turcq, B.; Nicolini, F.; Belanger, C.; Manley, P.W.; Leroy, C.; Etienne, G.; et al Evidence That Resistance to Nilotinib May Be Due to BCR-ABL, Pgp, or Src Kinase Overexpression. Cancer Res. 2008, 68, 9809-9816. [CrossRef]

59. Burger, H.; van Tol, H.; Boersma, A.W.M.; Brok, M.; Wiemer, E.A.C.; Stoter, G.; Nooter, K. Imatinib Mesylate (STI571) Is a Substrate for the Breast Cancer Resistance Protein (BCRP)/ABCG2 Drug Pump. Blood 2004, 104, 2940-2942. [CrossRef]

60. Brendel, C.; Scharenberg, C.; Dohse, M.; Robey, R.W.; Bates, S.E.; Shukla, S.; Ambudkar, S.V.; Wang, Y.; Wennemuth, G.; Burchert, A.; et al. Imatinib Mesylate and Nilotinib (AMN107) Exhibit High-Affinity Interaction with ABCG2 on Primitive Hematopoietic Stem Cells. Leukemia 2007, 21, 1267-1275. [CrossRef]

61. Hiwase, D.K.; Saunders, V.; Hewett, D.; Frede, A.; Zrim, S.; Dang, P.; Eadie, L.; To, L.B.; Melo, J.; Kumar, S.; et al. Dasatinib Cellular Uptake and Efflux in Chronic Myeloid Leukemia Cells: Therapeutic Implications. Clin. Cancer Res. Off. J. Am. Assoc. Cancer Res. 2008, 14, 3881-3888. [CrossRef]

62. Balabanov, S.; Gontarewicz, A.; Keller, G.; Raddrizzani, L.; Braig, M.; Bosotti, R.; Moll, J.; Jost, E.; Barett, C.; Rohe, I.; et al. Abcg2 Overexpression Represents a Novel Mechanism for Acquired Resistance to the Multi-Kinase Inhibitor Danusertib in BCR-ABL-Positive Cells In Vitro. PLoS ONE 2011, 6, e19164. [CrossRef] [PubMed]

63. Czyzewski, K.; Styczynski, J. Imatinib Is a Substrate for Various Multidrug Resistance Proteins. Neoplasma 2009, 56, $202-207$. [CrossRef] [PubMed]

64. Shibayama, Y.; Nakano, K.; Maeda, H.; Taguchi, M.; Ikeda, R.; Sugawara, M.; Iseki, K.; Takeda, Y.; Yamada, K. Multidrug Resistance Protein 2 Implicates Anticancer Drug-Resistance to Sorafenib. Biol. Pharm. Bull. 2011, 34, 433-435. [CrossRef] [PubMed]

65. Sims, J.T.; Ganguly, S.S.; Bennett, H.; Friend, J.W.; Tepe, J.; Plattner, R. Imatinib Reverses Doxorubicin Resistance by Affecting Activation of STAT3-Dependent NF-KB and HSP27/P38/AKT Pathways and by Inhibiting ABCB1. PLoS ONE 2013, 8, e55509. [CrossRef]

66. Houghton, P.J.; Germain, G.S.; Harwood, F.C.; Schuetz, J.D.; Stewart, C.F.; Buchdunger, E.; Traxler, P. Imatinib Mesylate Is a Potent Inhibitor of the ABCG2 (BCRP) Transporter and Reverses Resistance to Topotecan and SN-38 in Vitro. Cancer Res. 2004, 64, 2333-2337. [CrossRef]

67. Shukla, S.; Sauna, Z.E.; Ambudkar, S.V. Evidence for the Interaction of Imatinib at the Transport-Substrate Site(s) of the MultidrugResistance-Linked ABC Drug Transporters ABCB1 (P-Glycoprotein) and ABCG2. Leukemia 2008, 22, 445-447. [CrossRef] [PubMed]

68. Tiwari, A.K.; Sodani, K.; Dai, C.-L.; Abuznait, A.H.; Singh, S.; Xiao, Z.-J.; Patel, A.; Talele, T.T.; Fu, L.; Kaddoumi, A.; et al. Nilotinib Potentiates Anticancer Drug Sensitivity in Murine ABCB1-, ABCG2-, and ABCC10-Multidrug Resistance Xenograft Models. Cancer Lett. 2013, 328, 307-317. [CrossRef] 
69. Giannoudis, A.; Davies, A.; Lucas, C.M.; Harris, R.J.; Pirmohamed, M.; Clark, R.E. Effective Dasatinib Uptake May Occur without Human Organic Cation Transporter 1 (HOCT1): Implications for the Treatment of Imatinib-Resistant Chronic Myeloid Leukemia. Blood 2008, 112, 3348-3354. [CrossRef]

70. Sen, R.; Natarajan, K.; Bhullar, J.; Shukla, S.; Fang, H.-B.; Cai, L.; Chen, Z.-S.; Ambudkar, S.V.; Baer, M.R. The Novel BCR-ABL and FLT3 Inhibitor Ponatinib Is a Potent Inhibitor of the MDR-Associated ATP-Binding Cassette Transporter ABCG2. Mol. Cancer Ther. 2012, 11, 2033-2044. [CrossRef]

71. Kitazaki, T.; Oka, M.; Nakamura, Y.; Tsurutani, J.; Doi, S.; Yasunaga, M.; Takemura, M.; Yabuuchi, H.; Soda, H.; Kohno, S. Gefitinib, an EGFR Tyrosine Kinase Inhibitor, Directly Inhibits the Function of P-Glycoprotein in Multidrug Resistant Cancer Cells. Lung Cancer 2005, 49, 337-343. [CrossRef] [PubMed]

72. Kuang, Y.-H.; Shen, T.; Chen, X.; Sodani, K.; Hopper-Borge, E.; Tiwari, A.K.; Lee, J.W.K.K.; Fu, L.-W.; Chen, Z.-S. Lapatinib and Erlotinib Are Potent Reversal Agents for MRP7 (ABCC10)-Mediated Multidrug Resistance. Biochem. Pharmacol. 2010, 79, 154-161. [CrossRef]

73. Dai, C.; Liang, Y.; Wang, Y.; Tiwari, A.K.; Yan, Y.; Wang, F.; Chen, Z.; Tong, X.; Fu, L. Sensitization of ABCG2-Overexpressing Cells to Conventional Chemotherapeutic Agent by Sunitinib Was Associated with Inhibiting the Function of ABCG2. Cancer Lett. 2009, 279, 74-83. [CrossRef] [PubMed]

74. Shukla, S.; Robey, R.W.; Bates, S.E.; Ambudkar, S. V Sunitinib (Sutent, SU11248), a Small-Molecule Receptor Tyrosine Kinase Inhibitor, Blocks Function of the ATP-Binding Cassette (ABC) Transporters P-Glycoprotein (ABCB1) and ABCG2. Drug Metab. Dispos. 2009, 37, 359-365. [CrossRef] [PubMed]

75. Anreddy, N.; Patel, A.; Sodani, K.; Kathawala, R.J.; Chen, E.P.; Wurpel, J.N.D.; Chen, Z.-S. PD173074, a Selective FGFR Inhibitor, Reverses MRP7 (ABCC10)-Mediated MDR. Acta Pharm. Sin. B. 2014, 4, 202-207. [CrossRef]

76. Huang, W.; Zhang, J.; Dong, B.; Chen, H.; Shao, L.; Li, X. A Novel MiR-98 Negatively Regulates the Resistance of Endometrial Cancer Cells to Paclitaxel by Suppressing ABCC10/MRP-7. Front. Oncol. 2021, 11, 809410. [CrossRef] [PubMed]

77. Hopper-Borge, E.; Chen, Z.-S.; Shchaveleva, I.; Belinsky, M.G.; Kruh, G.D. Analysis of the Drug Resistance Profile of Multidrug Resistance Protein 7 (ABCC10): Resistance to Docetaxel. Cancer Res. 2004, 64, 4927-4930. [CrossRef]

78. Oguri, T.; Ozasa, H.; Uemura, T.; Bessho, Y.; Miyazaki, M.; Maeno, K.; Maeda, H.; Sato, S.; Ueda, R. MRP7/ABCC10 Expression Is a Predictive Biomarker for the Resistance to Paclitaxel in Non-Small Cell Lung Cancer. Mol. Cancer Ther. 2008, 7, 1150-1155. [CrossRef]

79. Domanitskaya, N.; Wangari-Talbot, J.; Jacobs, J.; Peiffer, E.; Mahdaviyeh, Y.; Paulose, C.; Malofeeva, E.; Foster, K.; Cai, K.Q.; Zhou, Y.; et al. Abcc10 Status Affects Mammary Tumour Growth, Metastasis, and Docetaxel Treatment Response. Br. J. Cancer 2014, 111, 696-707. [CrossRef]

80. Hopper-Borge, E.A.; Churchill, T.; Paulose, C.; Nicolas, E.; Jacobs, J.D.; Ngo, O.; Kuang, Y.; Grinberg, A.; Westphal, H.; Chen, Z.-S.; et al. Contribution of Abcc10 (Mrp7) to In Vivo Paclitaxel Resistance as Assessed in Abcc10-/ - Mice. Cancer Res. 2011, 71, 3649-3657. [CrossRef]

81. Wattel, E.; Solary, E.; Hecquet, B.; Caillot, D.; Ifrah, N.; Brion, A.; Milpied, N.; Janvier, M.; Guerci, A.; Rochant, H.; et al. Quinine Improves Results of Intensive Chemotherapy (IC) in Myelodysplastic Syndromes (MDS) Expressing P-Glycoprotein (PGP) Updated Results of a Randomized Study. Groupe Français Des Myélodysplasies (GFM) and Groupe GOELAMS. Adv. Exp. Med. Biol. 1999, 457, 35-46. [CrossRef] [PubMed]

82. Wilson, W.H.; Bates, S.E.; Fojo, A.; Bryant, G.; Zhan, Z.; Regis, J.; Wittes, R.E.; Jaffe, E.S.; Steinberg, S.M.; Herdt, J. Controlled Trial of Dexverapamil, a Modulator of Multidrug Resistance, in Lymphomas Refractory to EPOCH Chemotherapy. J. Clin. Oncol. 1995, 13, 1995-2004. [CrossRef] [PubMed]

83. Sonneveld, P.; Suciu, S.; Weijermans, P.; Beksac, M.; Neuwirtova, R.; Solbu, G.; Lokhorst, H.; Van Der Lelie, J.; Dohner, H.; Gerhartz, H.; et al. Cyclosporin A Combined with Vincristine, Doxorubicin and Dexamethasone (VAD) Compared with VAD Alone in Patients with Advanced Refractory Multiple Myeloma: An EORTC-HOVON Randomized Phase III Study (06914). Br. J. Haematol. 2001, 115, 895-902. [CrossRef]

84. Liu Yin, J.A.; Wheatley, K.; Rees, J.K.H.; Burnett, A.K.; UK MRC Adult Leukaemia Working Party. Comparison of 'Sequential' versus 'Standard' Chemotherapy as Re-Induction Treatment, with or without Cyclosporine, in Refractory/Relapsed Acute Myeloid Leukaemia (AML): Results of the UK Medical Research Council AML-R Trial. Br. J. Haematol. 2001, 113, 713-726. [CrossRef]

85. Friedenberg, W.R.; Rue, M.; Blood, E.A.; Dalton, W.S.; Shustik, C.; Larson, R.A.; Sonneveld, P.; Greipp, P.R. Phase III Study of PSC-833 (Valspodar) in Combination with Vincristine, Doxorubicin, and Dexamethasone (Valspodar/VAD) versus VAD Alone in Patients with Recurring or Refractory Multiple Myeloma (E1A95). Cancer 2006, 106, 830-838. [CrossRef] [PubMed]

86. Kolitz, J.E.; George, S.L.; Dodge, R.K.; Hurd, D.D.; Powell, B.L.; Allen, S.L.; Velez-Garcia, E.; Moore, J.O.; Shea, T.C.; Hoke, E.; et al. Dose Escalation Studies of Cytarabine, Daunorubicin, and Etoposide With and Without Multidrug Resistance Modulation With PSC-833 in Untreated Adults With Acute Myeloid Leukemia Younger Than 60 Years: Final Induction Results of Cancer and Leukemia Group B. J. Clin. Oncol. 2004, 22, 4290-4301. [CrossRef]

87. Greenberg, P.L.; Lee, S.J.; Advani, R.; Tallman, M.S.; Sikic, B.I.; Letendre, L.; Dugan, K.; Lum, B.; Chin, D.L.; Dewald, G.; et al Mitoxantrone, Etoposide, and Cytarabine with or without Valspodar in Patients with Relapsed or Refractory Acute Myeloid Leukemia and High-Risk Myelodysplastic Syndrome: A Phase III Trial (E2995). J. Clin. Oncol. 2004, 22, 1078-1086. [CrossRef] 
88. Lhommé, C.; Joly, F.; Walker, J.L.; Lissoni, A.A.; Nicoletto, M.O.; Manikhas, G.M.; Baekelandt, M.M.O.; Gordon, A.N.; Fracasso, P.M.; Mietlowski, W.L.; et al. Phase III Study of Valspodar (PSC 833) Combined With Paclitaxel and Carboplatin Compared With Paclitaxel and Carboplatin Alone in Patients With Stage IV or Suboptimally Debulked Stage III Epithelial Ovarian Cancer or Primary Peritoneal Cancer. J. Clin. Oncol. 2008, 26, 2674-2682. [CrossRef]

89. Ten Tije, A.J.; Synold, T.W.; Spicer, D.; Verweij, J.; Doroshow, J.H.; Sparreboom, A. Effect of Valspodar on the Pharmacokinetics of Unbound Paclitaxel. Investig. New Drugs 2003, 21, 291-298. [CrossRef]

90. Abraham, J.; Edgerly, M.; Wilson, R.; Chen, C.; Rutt, A.; Bakke, S.; Robey, R.; Dwyer, A.; Goldspiel, B.; Balis, F.; et al. A Phase I Study of the P-Glycoprotein Antagonist Tariquidar in Combination with Vinorelbine. Clin. Cancer Res. 2009, 15, $3574-3582$. [CrossRef]

91. Gerrard, G.; Payne, E.; Baker, R.J.; Jones, D.T.; Potter, M.; Prentice, H.G.; Ethell, M.; McCullough, H.; Burgess, M.; Mehta, A.B.; et al. Clinical Effects and P-Glycoprotein Inhibition in Patients with Acute Myeloid Leukemia Treated with Zosuquidar Trihydrochloride, Daunorubicin and Cytarabine. Haematologica 2004, 89, 782-790. [CrossRef]

92. Ruff, P.; Vorobiof, D.A.; Jordaan, J.P.; Demetriou, G.S.; Moodley, S.D.; Nosworthy, A.L.; Werner, I.D.; Raats, J.; Burgess, L.J. A Randomized, Placebo-Controlled, Double-Blind Phase 2 Study of Docetaxel Compared to Docetaxel plus Zosuquidar (LY335979) in Women with Metastatic or Locally Recurrent Breast Cancer Who Have Received One Prior Chemotherapy Regimen. Cancer Chemother. Pharmacol. 2009, 64, 763. [CrossRef]

93. Holló, Z.; Homolya, L.; Davis, C.W.; Sarkadi, B. Calcein Accumulation as a Fluorometric Functional Assay of the Multidrug Transporter. Biochim. Biophys. Acta 1994, 1191, 384-388. [CrossRef]

94. Forster, S.; Thumser, A.E.; Hood, S.R.; Plant, N. Characterization of Rhodamine-123 as a Tracer Dye for Use in in Vitro Drug Transport Assays. PLoS ONE 2012, 7, e33253. [CrossRef]

95. Beretta, G.L.; Cassinelli, G.; Pennati, M.; Zuco, V.; Gatti, L. Overcoming ABC Transporter-Mediated Multidrug Resistance: The Dual Role of Tyrosine Kinase Inhibitors as Multitargeting Agents. Eur. J. Med. Chem. 2017, 142, 271-289. [CrossRef] [PubMed]

96. Wang, S.; Liu, S.; Zhao, B.; Yang, F.; Wang, Y.; Liang, Q.-Y.; Sun, Y.; Liu, Y.; Song, Z.; Cai, Y.; et al. Afatinib Reverses Multidrug Resistance in Ovarian Cancer via Dually Inhibiting ATP Binding Cassette Subfamily B Member 1. Oncotarget 2015, 6, 26142-26160. [CrossRef] [PubMed]

97. Krchniakova, M.; Skoda, J.; Neradil, J.; Chlapek, P.; Veselska, R. Repurposing Tyrosine Kinase Inhibitors to Overcome Multidrug Resistance in Cancer: A Focus on Transporters and Lysosomal Sequestration. Int. J. Mol. Sci. 2020, 21, 3157. [CrossRef]

98. Walker, J.E.; Saraste, M.; Runswick, M.J.; Gay, N.J. Distantly Related Sequences in the Alpha- and Beta-Subunits of ATP Synthase, Myosin, Kinases and Other ATP-Requiring Enzymes and a Common Nucleotide Binding Fold. EMBO J. 1982, 1, $945-951$. [CrossRef]

99. Taylor, S.S.; Kornev, A.P. Protein Kinases: Evolution of Dynamic Regulatory Proteins. Trends Biochem. Sci. 2011, 36, 65-77. [CrossRef]

100. Loo, T.W.; Bartlett, M.C.; Clarke, D.M. Transmembrane Segment 7 of Human P-Glycoprotein Forms Part of the Drug-Binding Pocket. Biochem. J. 2006, 399, 351-359. [CrossRef]

101. Loo, T.W.; Clarke, D.M. Thiol-Reactive Drug Substrates of Human P-Glycoprotein Label the Same Sites to Activate ATPase Activity in Membranes or Dodecyl Maltoside Detergent Micelles. Biochem. Biophys. Res. Commun. 2017, 488, 573-577. [CrossRef]

102. Wu, C.-P.; Hung, T.-H.; Hsiao, S.-H.; Huang, Y.-H.; Hung, L.-C.; Yu, Y.-J.; Chang, Y.-T.; Wang, S.-P.; Wu, Y.-S. Erdafitinib Resensitizes ABCB1-Overexpressing Multidrug-Resistant Cancer Cells to Cytotoxic Anticancer Drugs. Cancers 2020, $12,1366$. [CrossRef] [PubMed]

103. Kim, S.H.; Ryu, H.; Ock, C.-Y.; Suh, K.J.; Lee, J.Y.; Kim, J.-W.; Lee, J.-O.; Kim, J.W.; Kim, Y.J.; Lee, K.-W.; et al. BGJ398, A Pan-FGFR Inhibitor, Overcomes Paclitaxel Resistance in Urothelial Carcinoma with FGFR1 Overexpression. Int. J. Mol. Sci. 2018, 19, 3164. [CrossRef] [PubMed]

104. Santolla, M.F.; Vivacqua, A.; Lappano, R.; Rigiracciolo, D.C.; Cirillo, F.; Galli, G.R.; Talia, M.; Brunetti, G.; Miglietta, A.M.; Belfiore, A.; et al. GPER Mediates a Feedforward FGF2/FGFR1 Paracrine Activation Coupling CAFs to Cancer Cells toward Breast Tumor Progression. Cells 2019, 8, 223. [CrossRef] [PubMed]

105. Reis-Filho, J.S.; Simpson, P.T.; Turner, N.C.; Lambros, M.B.; Jones, C.; Mackay, A.; Grigoriadis, A.; Sarrio, D.; Savage, K.; Dexter, T.; et al. FGFR1 Emerges as a Potential Therapeutic Target for Lobular Breast Carcinomas. Clin. Cancer Res. Off. J. Am. Assoc. Cancer Res. 2006, 12, 6652-6662. [CrossRef]

106. Santolla, M.F.; Maggiolini, M. The FGF/FGFR System in Breast Cancer: Oncogenic Features and Therapeutic Perspectives. Cancer 2020, 12, 3029. [CrossRef]

107. Boichuk, S.; Galembikova, A.; Dunaev, P.; Valeeva, E.; Shagimardanova, E.; Gusev, O.; Khaiboullina, S. A Novel Receptor Tyrosine Kinase Switch Promotes Gastrointestinal Stromal Tumor Drug Resistance. Molecules 2017, 22, 2152. [CrossRef]

108. Boichuk, S.; Galembikova, A.; Dunaev, P.; Micheeva, E.; Valeeva, E.; Novikova, M.; Khromova, N.; Kopnin, P. Targeting of FGF-Signaling Re-Sensitizes Gastrointestinal Stromal Tumors (GIST) to Imatinib In Vitro and In Vivo. Molecules 2018, $23,2152$. [CrossRef] [PubMed]

109. Boichuk, S.; Dunaev, P.; Galembikova, A.; Bikinieva, F.; Nurgatina, I.; Mustafin, I.; Aukhadieva, A.; Kurtasanov, R.; Andriutsa, N.; Shagimardanova, E.; et al. Inhibition of FGFR2-Signaling Attenuates a Homology-Mediated DNA Repair in GIST and Sensitizes Them to DNA-Topoisomerase II Inhibitors. Int. J. Mol. Sci. 2020, 21, 352. [CrossRef] 